\title{
Sustainable
}

Development Commission

\section{Policies for sustainable consumption}

A report to the

Sustainable Development Commission

by Tim Jackson and Laurie Michaelis 


\title{
Policies for \\ Sustainable Consumption
}

\author{
a report to the \\ Sustainable Development Commission
}

20th May 2003

Tim Jackson

Centre for Environmental Strategy

University of Surrey

t.jackson@surrey.ac.uk

Laurie Michaelis

Environmental Change Institute

Oxford University

laurie.michaelis@eci.ox.ac.uk 


\section{Contents}

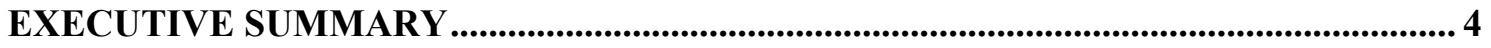

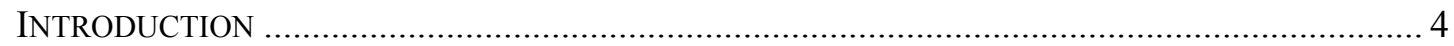

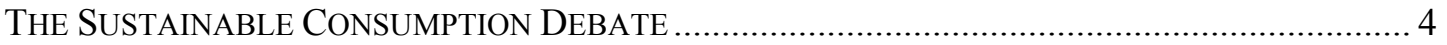

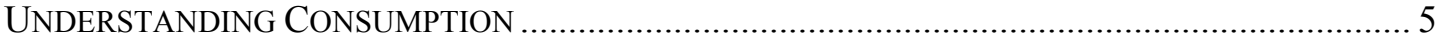

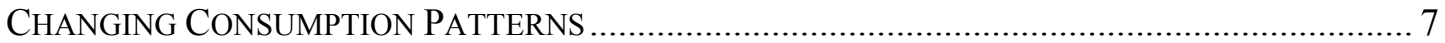

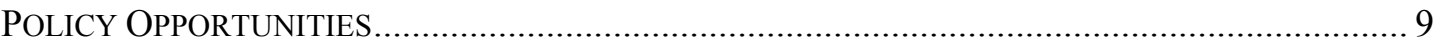

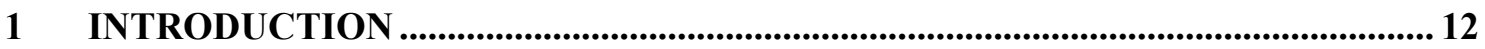

2 THE SUSTAINABLE CONSUMPTION DEBATE ................................................ 13

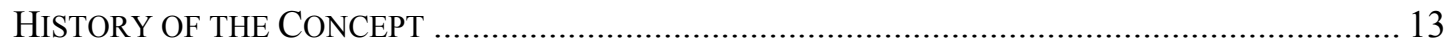

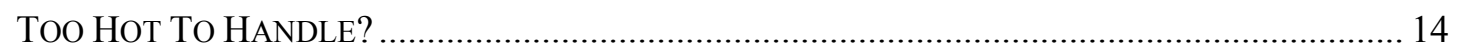

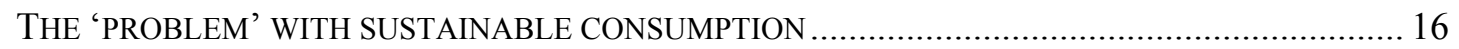

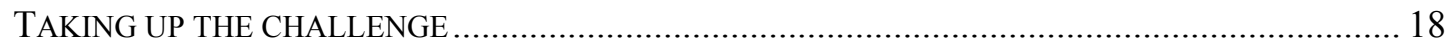

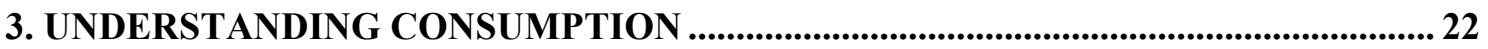

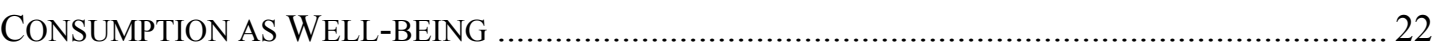

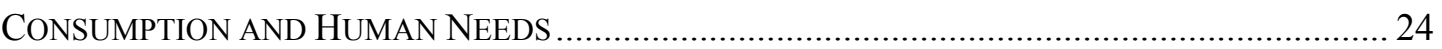

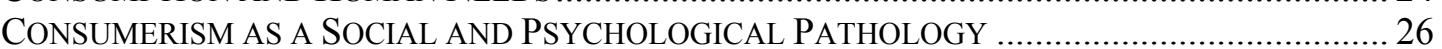

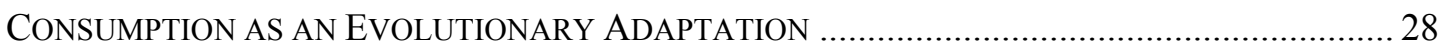

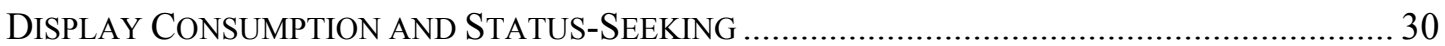

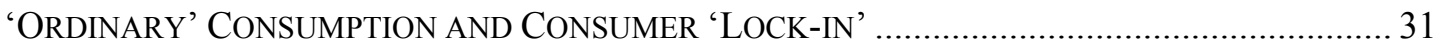

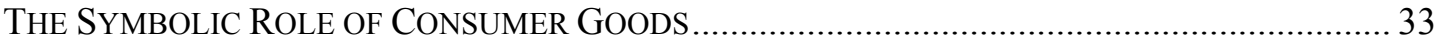

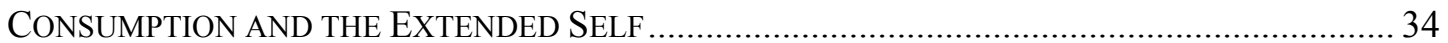

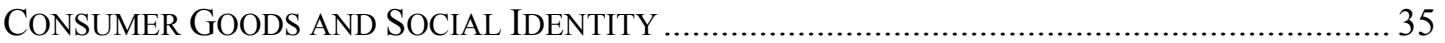

CONSUMPTION AND THE PURSUIT OF MEANING.................................................................. 36

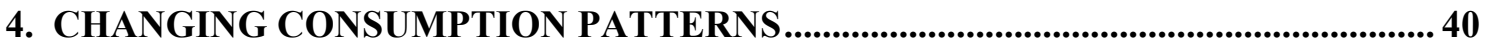

CONSUMPTION DIFFERENCES AND CHANGE PROCESSES ...................................................... 40

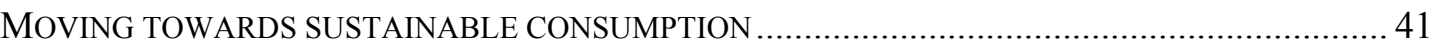

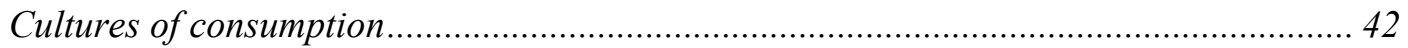

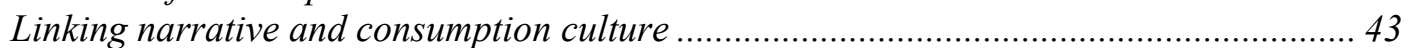

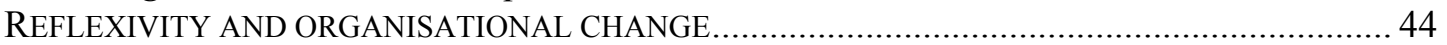

Changing consumption in reflexive communities ........................................................... 45

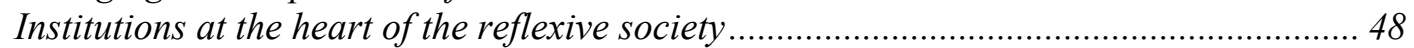

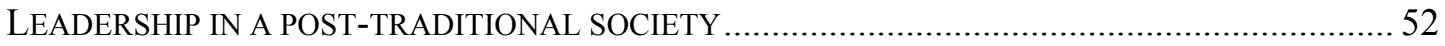

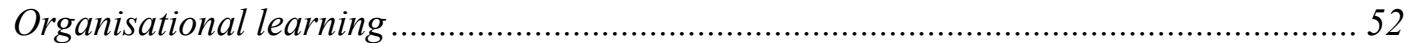

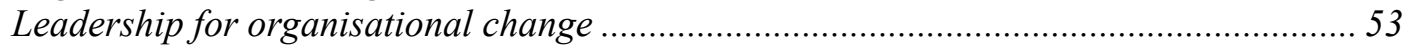

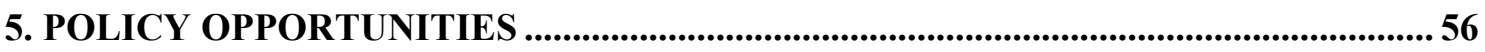

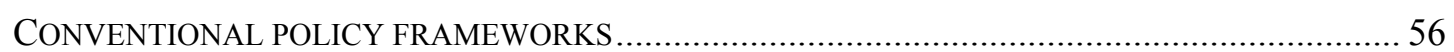

Instrumental policies: "government in control"................................................................ 56

Information and persuasion: government as expert and moral guide ...............................5 59

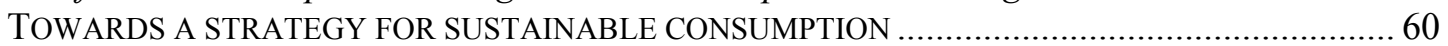

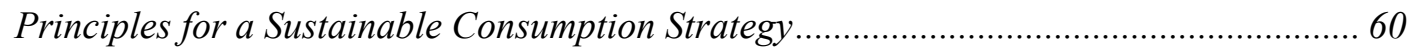

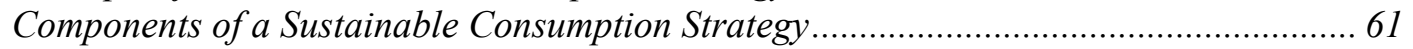

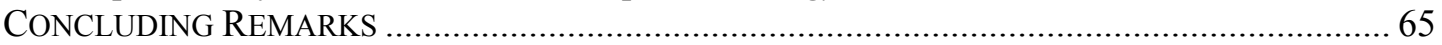

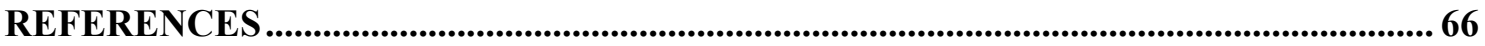




\section{Acknowledgements}

The authors gratefully acknowledge the support of the ESRC Sustainable Technology Programme, the Joseph Rowntree Charitable Trust, Mr Paul Hannam, and the Sustainable Development Commission in the research underlying this report and in its preparation. 


\section{Executive Summary}

\section{Introduction}

There is an emerging recognition of the importance of consumption within the sustainability debate. The term 'sustainable consumption' has been coined to reflect this emphasis.

In pursuit of its advocacy remit, the Sustainable Development Commission is currently seeking to influence government policy on sustainable consumption, specifically with regard to DEFRA's forthcoming Sustainable Consumption and Production strategy and other UK policy developments.

The purpose of this document is to enhance that process. It aims to provide a guide to the complexity of the sustainable consumption debate, an overview of the extensive literatures on consumer behaviour and lifestyle change, and an analysis of the policy opportunities suggested by these literatures.

\section{The Sustainable Consumption Debate}

Consumption has been an important issue in international policy since the early 1970s. The terminology of sustainable consumption entered the policy discourse in 1992 at the Rio Earth Summit. In the decade following the Rio Summit, a wide variety of institutional programmes on sustainable consumption were initiated.

The success of these initiatives has been mixed. It has proved difficult to agree either on a precise definition of sustainable consumption or on the domain of application of the concept. Different institutions have proposed widely different definitions. Differences between these definitions tend to revolve around the question of whether sustainable consumption means consuming differently, consuming responsibly or consuming less.

The current institutional consensus has tended to settle for a position which implies consuming differently rather than consuming less, and in which this is to be achieved primarily by the production and sale of more sustainable products. This position is problematic because it collapses the distinction between sustainable consumption and sustainable production. It also fails to address important questions about the scale of consumption, the nature of consumer behaviour and the relevance of lifestyle change.

Institutional reticence to address these latter issues appears to hinge on three concerns. In the first place, addressing them properly would involve questioning fundamental assumptions about the way modern society functions. In the second place, any attempt to address consumption quickly becomes reflexive and challenges us at the level of personal change. Finally, questioning consumption appears to threaten a wide variety of vested interests.

In spite of these concerns, there are a number of very strong reasons for a concerted effort to address consumption. Inequality in the distribution of consumption goods is perhaps the most widely accepted of these reasons. Environmental impacts arising from the scale of consumption are another important concern. Finally, there is a body of 
thought which questions whether consumption (and consumerism in particular) actually contributes to human well-being and flourishing.

Taken together these reasons constitute a compelling reason not to shy away from the problem of consumption. There is increasing agreement on this fact from a wide academic and policy literature. It may not be possible to agree a definition of sustainable consumption. But confronting consumption, seeking to influence consumer behaviour, and understanding the process of lifestyle change are increasingly important topics for sustainable development.

\section{Understanding Consumption}

The debate about sustainable consumption cannot be understood in isolation from older debates about consumer behaviour, consumer society and consumerism. These older debates are embedded in a long and complex literature deriving from disciplines as diverse as consumer research, psychology, sociology, social philosophy, anthropology, and economics. Part 3 of this report aims to provide an overview of this literature. It draws out key findings and points to the relevance of these findings for sustainable consumption policy.

\section{Consumption and Well-Being}

In some simple sense, consumption can be viewed as an attempt to provide for individual and collective well-being. This is the view encoded in conventional economics. Stressing the 'insatiability' of consumer desire and the 'sovereignty' of consumer choice, economics is virtually silent on the underlying motivations for those choices and desires. The policy options suggested by this view are well-known, but limited.

A contrasting view of the relationship between consumption and well-being draws on modern theories of human needs. Needs theorists suggest, in contrast to the 'insatiability' of desire, that 'true' human needs are finite, few and universal. They distinguish between material needs and social or psychological needs. An important concept is the notion of false satisfiers. An important question is whether material commodities are true or false satisfiers of social and psychological needs.

The possibility that some of what we consume does not satisfy our needs provides the basis for a long-standing critique of consumer society. According to this critique, the consumer way of life is 'deeply flawed, both ecologically and psychologically'. Recent evidence that quality of life measures do not correlate with rising income, and that materialistic values impede life-satisfaction tend to support this critique.

Proponents of this view see consumerism as a social and psychological pathology. They suggest that we ought to be able to live better by consuming less. However, this critique begs the question: why, if consumerism fails to satisfy, do we continue to consume?

\section{Consumption as an Evolutionary Adaptation}

One answer to this question is to be found in modern theories of evolutionary psychology, which suggests that consumer behaviour is conditioned in part at least by sexual competition. The idea that consumption has something to do with sexual desire 
is borne out by sociological research and clearly resonates with the common wisdom of advertising executives. However, the theory also offers an account of cooperative and moral behaviours. Importantly, these aspects of the theory suggest that individual choices between competitive and cooperative behaviour depend crucially on the social climate. Government has a vital role in shaping this climate.

Amongst the behaviours predicted by evolutionary psychology are display and statusseeking behaviours. Such behaviours have been the focus of sociological discourses on consumption for well over a century. Veblen's notion of conspicuous consumption, and Hirsch's concept of positional goods both point to the importance of material goods in social positioning. Hirsch also points to the dynamic nature of this kind of consumption. We must run faster and faster to stay in the same place, because our competitors are also engaged in the race. Though evolutionary psychology appears to offer some legitimation for this behaviour, social critics argue that it remains pathological. Policy suggestions include reducing the incentive for positional consumption, addressing social inequality and promoting social and ethical 'goods'.

\section{'Ordinary' Consumption and Consumer 'Lock-in'}

Some recent work argues that conspicuous and status-seeking aspects of consumer behaviour have been overemphasised. Ordinary, every-day consumption, argue these authors, is not particularly oriented towards display. Rather it is about convenience, habit, practice, and individual responses to social and institutional norms. Far from being willing partners in the process of consumerism, consumers are seen as being 'locked-in' to a process of unsustainable consumption over which they have very little individual control. This perspective identifies a vital role for government in shifting the institutional architecture of consumer 'lock-in'.

\section{The Symbolic Role of Consumer Goods}

In spite of these reservations, there is one feature of display consumption which has much wider connotations than its application to status-seeking behaviours. This is the insight that consumer goods play vital symbolic roles in our lives. Drawing inspiration from anthropology and social philosophy this idea also has a popular resonance. We value goods not just for what they can do, but for what they represent to us and to others.

The explanatory uses of this hypothesis are diverse. One of its applications lies in understanding the role of commodities in constructing and maintaining personal identity. The symbolic properties of goods allow us to see material possessions as part of our 'extended self'. Some authors see the continual construction and reconstruction of identity through consumption as a defining feature of modernity

However, the symbolic importance of commodities is not confined to the construction of personal identity. Goods also communicate belongingness, affiliation, group identity, allegiance to particular ideals, distance from certain other ideals. Douglas and Isherwood drew attention to the role of goods in providing 'marking services' - social rituals that serve to embed the individual within their social group. This view provides one of the clearest messages that simplistic appeals to forego consumption will not work. In a society in which goods provide vitally important sources of social 
information, giving them up is not an option. A more sophisticated policy approach is vital.

Equally important are the insights that connect the symbolic role of consumer goods to our 'higher' self-actualisation needs. There is evidence that material goods occupy a vital role in the search for meaning in our lives. Consumerism occupies a role once fulfilled by religion, allowing us to construct narratives and rituals to make sense of our lives, and to protect the ideals we wish to live by. Though our attempts to achieve this ultimately fail, the role of consumer goods in this respect is an important and persuasive one.

\section{Changing Consumption Patterns}

We appear to be locked into current consumption trends by a combination of past choices, technology, economic incentives, institutions, our own psychology and the culture and social systems we inhabit. But the culture of consumption does evolve, and has changed radically in recent decades. Technology sometimes seems to be the main driver, but consumption patterns and choices also shape technology. Some of the last half-century's developments have been the result of deliberate government policies. We are even sometimes able to give up habits that harm us.

\section{Diversity and change in consumption patterns}

Consumption patterns are very diverse. This diversity is itself a force for change. New consumption trends and fashions can spread from small groups, especially when they are taken up by media celebrities, or promoted by business, government and other institutions. There is some evidence of international convergence in aspirations towards an affluent middle class lifestyle, but diversity is not diminishing in actual consumption patterns. It offers hope for the spread of more sustainable consumption patterns, already adopted or maintained by minority groups.

In Britain, a small minority of citizens make considerable efforts to consume as sustainably as possible. A larger, growing minority is choosing ethical products. The majority share a concern for social and environmental issues but place a low priority on them in their current consumption choices. These consumption patterns are correlated with other aspects of culture. Understanding the various cultures of consumption and the values, worldviews and narratives that underlie them would help the Government in developing an effective strategy for sustainable consumption and production. The groups differ in their conceptions of sustainable development, in the role played by consumption in their lives, and in the contextual factors that influence their choices. Some groups would respond best to market incentives, others to information and opportunities for engagement, and still others are unlikely to change their habits unless forced by regulation.

\section{Reflexivity and change}

One of the main sources of hope for a shift towards a sustainable society is the growth in reflexivity. Society is becoming "post-traditional" with the increasing selfquestioning of institutions, reflecting on and discussing cultural assumptions and norms. A reflexive institution is basically one that has a consciously evolving story about itself. 
Discourse and narrative are central to reflexivity and provide a bridge from collective culture to individual psychology.

The sustainability challenge is one of the motivations for increasing reflexivity in communities and organisations. In Britain, a variety of movements and networks have developed, in which participants meet in small groups to learn about environmental and social issues, explore lifestyle options, and take collective action.

Through mutual support in developing their own culture of consumption, such groups have achieved and sustained significant reductions in household resource use and waste. At the same time they have strengthened their sense of community involvement, personal fulfilment and quality of life. However, there is a limit to the change that can be achieved by small community groups unless there is a change in the wider context of culture, social structure, markets and infrastructure.

Certain institutions play a particularly important role in the shaping of these contextual factors. The media are often identified as key players. However there is an ongoing debate about the extent to which the media shapes culture, and the extent to which it reflects it. Both are true to some degree, but the media play a crucial role as gatekeepers in the cycling of the narratives and symbolism that helps to shape consumption.

Schools contribute to culture both through teaching the curriculum and through acting as communities in their own right. Some schools are exemplary in demonstrating the principles of sustainability, and reaching out to the wider community. However, schools themselves are tightly constrained in their scope for experimentation and leadership by the infrastructure they have inherited and by the institutional framework and goals imposed on them by the government.

Businesses shape consumption through the products and services they offer, by shaping the cultural context for consumption through marketing, and by shaping household time and financial budgets through employment. In the sustainable development agenda, businesses have seen their main contribution as the development of more eco-efficient products and services. A shift towards sustainable consumption would require them to re-examine their role in society at a much deeper level.

\section{Leadership in a post-traditional society}

The role of government is changing from one of direction and control to one of "change management". There is much to be learned from the growing field of research on organisational change. Seeking ways of living that enable individuals, the collective, and nature to flourish must be a learning process for the whole of society. It is likely to mean letting go of the assumption that change can be controlled, and recognising that the learning process may be a very personal one for those in leadership roles, as well as others. Learning may challenge our own assumptions about ourselves and our psychology, it may challenge norms of interactions within groups, and it may challenge our assumptions about the wider world.

In organisational change, the reflective process needs to address several realms. It must address the shared vision for the flourishing of the organisation, group or society; it 
must develop a strategy to achieve that vision; it must focus on responsibilities for specific, concrete actions; and it must include a mechanism for monitoring and evaluation. These are the key components in developing any strategy for sustainable consumption.

The leadership role in a learning organisation is a challenging one. Above all, it demands an ability and willingness on the part of the leaders to listen and learn, and compassion and understanding for the worldviews of others. This cannot work while the leader is an unreflecting advocate for a particular point of view. Leadership becomes service to the needs of the whole.

\section{Policy Opportunities}

The final section of this report explores the policy opportunities that flow from a broader and deeper understanding of the sustainable consumption debate. It briefly outlines conventional policy positions and then goes on to develop the basis for a strategic approach to sustainable consumption policy.

\section{Conventional policy frameworks}

The conventional view of sustainable consumption policy is based on one of two specific roles for government.

The first role is one in which government seeks to understand and influence consumer behaviour from the outside. The government is understood as the manager of the system. Consumers are understood as entities with behaviour that is to some degree explicable and responsive to stimuli in predictable ways. Measures in this set include: regulations and standards, market instruments and planning.

The second role is one in which government seeks to influence consumers through information, education and other psychological measures. Measures in this set include the use of taxes and criminal law to send a deterrent signal or strong moral message. There is a great deal of experience with such measures, especially in areas such as health, safety, nutrition and addiction. Governments have long used the education system, media messages, media regulation, and labelling to try and persuade people to consume differently. In these cases, government is behaving as an expert advisor, moral guide, or surrogate parent.

Towards a strategy for sustainable consumption

Conventional policy measures are unlikely to achieve the scale or pace of consumption change needed to move towards a sustainable society. In addition, they tend to underestimate the complexity of underlying motivations, and ignore the diversity of ways in which government can engage in the processes that shape consumption. The final section of the report offers the basis for a strategic approach to sustainable consumption policy.

The starting point for this strategy is the identification of six policy lessons derived from the literature and research reviewed in this document. The first three of these lessons flow mainly from Part 3. The last three are derived from Part 4. 
1. Current government policy misconstrues the relationship between material commodities and quality of life. A shift in government policy would be justified to place more emphasis on other contributors to quality of life, such as health, community engagement and meaningful work.

2. Current thinking suggests that it would be infeasible for government to change individual consumer behaviours. Research does not support this presumption. Government plays a vital role in shaping the cultural context within which individual choice is negotiated through its influence on technology, market design, institutional structures, the media, and the moral framing of social goods.

3. Current government policy assumes that the market offers consumers the freedom to choose the lifestyle that best reflects their needs and desires. Research does not support this presumption. Consumers often find themselves 'locked in' to unsustainable consumption. Government intervention is vital to facilitate change.

4. A variety of movements and networks have developed in Britain, in which small groups learn about environmental and social issues, explore lifestyle options and take collective action. Their scope to demonstrate sustainable lifestyles would be greatly increased by government policies to establish a more supportive context.

5. The government role in our post-traditional society is shifting from control to a "change management" approach, encouraging learning. Successful leadership requires government to listen to others and question its own assumptions and practices.

6. To develop an effective strategy for sustainable consumption, the government will need to work on a collaborative basis with stakeholders to develop congruent visions, strategies, practical actions, and evaluation processes.

Finally, the report offers several key avenues for sustainable consumption policy, emphasising the role for government in:

- aligning vision and rhetoric with policy and practice;

- shaping the cultural context of consumption;

- supporting non-governmental initiatives for change and innovation;

- establishing programmes, agencies and networks to nurture successful initiatives and encourage their replication; and

- establishing an on-going process of review and collaborative learning.

These suggestions depart from conventional policy prescription in two specific ways. In the first place, they emphasise the vital role that government has to play in shaping the institutional, social, cultural and ethical context within which individual consumer behaviour is negotiated. Secondly, they offer a model for government policy which 
goes beyond the rigidity of 'control' and 'persuasion' and is based instead on the idea of government and public as collaborators and learning partners in the process of change. 


\section{Introduction}

There is an increasing recognition that increases in resource productivity alone will be insufficient to deliver sustainable development. Shifts in the scale and pattern of consumption are also likely to be essential. Achieving the latter relies on being able to influence not only the efficiency of industry, the performance of business and the design of products, but also the expectations, choices, behaviours and (possibly) the lifestyles of consumers. These issues are key components within the emerging concept of 'sustainable consumption'.

The Sustainable Development Commission has already taken the vanguard in relation to this emerging realisation. Position papers by Jonathon Porritt (2002), Roger Levett et al (2002) and Tom Hargreaves (2003) have all drawn attention to the importance of consumption, consumer choice and consumer behaviour in achieving sustainable development, and pointed to an urgent need for policies to address these issues. The Commission is therefore well-positioned to offer a timely input to the emerging sustainable consumption agenda.

The purpose of this document is to provide the Commission with a more detailed guide to the complexity that lies behind this important policy debate. In particular, by highlighting some of the less obvious policy opportunities arising from a more detailed understanding of consumption, the authors aim to enhance the Commission's ability to exert a robust and creative influence on DEFRA's Strategy for Sustainable Consumption and Production.

In pursuit of this aim, Part 2 of the report provides a brief policy history of the concept of sustainable consumption. It identifies the principal positions adopted in the debate, and describes the main tensions that have arisen between different protagonists. Part 3 offers a review of the broader debate on consumption, consumer behaviour and consumerism, within which the sustainable consumption debate sits. It highlights certain critical understandings about the nature of consumer behaviour and points to the relevance of these understandings for sustainable consumption policies. Part 4 focuses on the question of personal, organisational and institutional change. It summarises key insights from the conceptual literature on organisational change and social innovation. It also discusses a variety of real-life initiatives aimed at shifting consumption patterns. Part 5 synthesises the key insights from the previous sections and points towards the policy opportunities that arise from them. 


\section{The Sustainable Consumption Debate}

Part 2 of this report provides an overview of the sustainable consumption debate. In the first subsection we present a very brief history of the concept and terminology. In the second section we discuss how a decade of discussion has left the uncomfortable impression that sustainable consumption is somehow too hot to handle. In the following subsection, we explore some of the reasons for this. Finally, we set out several clear reasons for pursuing the consumption debate, in spite of the inherent complexities and difficulties that this involves us in.

\section{History of the Concept}

The terminology of sustainable consumption is recent. But the concept has been on the policy agenda for several decades at least. The Club of Rome's Limits to Growth report drew attention in 1972 to the impact that rising levels of affluence would have in terms of resource scarcity and environmental degradation. The oil price rises of 1973/4 and $1979 / 80$ seemed to confirm that business-as-usual consumption levels could not continue. Oil prices fell in the aftermath of the shocks, and predictions of resource scarcity failed to materialise. But the relevance of consumption patterns to pressing environmental problems such as climate change, ozone depletion and the management of hazardous waste had become increasingly obvious by the early 1990 s.

The term sustainable consumption itself can be dated more or less to Agenda 21 - the main policy document to emerge from the Rio Earth Summit in 1992. Chapter 4 of Agenda 21 was entitled 'Changing Consumption Patterns'. It called for 'new concepts of wealth and prosperity which allow higher standards of living through changed lifestyles and are less dependent on the Earth's finite resources'. In so doing, it provided a potentially far-reaching mandate for examining, questioning and revising consumption patterns - and, by implication, consumer behaviours, choices, expectations and lifestyles.

This mandate was initially taken up with some enthusiasm by the international policy community. In 1994, the Norwegian government hosted a roundtable on sustainable consumption in Oslo involving business, NGO and government representatives (Ofstad, 1994). The United Nations Commission on Sustainable Development (CSD) launched an international work programme on changing production and consumption patterns in 1995. At the 'Rio plus 5' conference in 1997, governments had identified sustainable consumption as an 'over-riding issue' and a 'cross-cutting theme' in the sustainable development debate.

By the late 1990s, initiatives on sustainable consumption were in full flood. The 1998 Human Development Report focused explicitly on the topic of consumption (UNDP 1998). In the same year, the Norwegian government organised a further workshop in Kabelvåg (IIED 1998). The government of South Korea hosted a follow-up conference in 1999. Sustainable consumption was given a special attention at the $7^{\text {th }}$ session of the CSD in 1999. In the same year, the Oxford Commission on Sustainable Consumption was launched with the aim of formulating an Action Plan on sustainable consumption for the World Summit on Sustainable Development (WSSD). The United Nations 
Environment Programme (UNEP) launched a sustainable consumption network, integrated sustainable consumption policies into the Consumer Protection Guidelines, and in 2001 published a strategic document emphasising the opportunities afforded by the new sustainable consumption focus (UNEP 2001). The following year, UNEP also published a strategic review of progress towards sustainable consumption. By the time WSSD convened in 2002, 'changing consumption and production patterns' had been identified as one of three 'overarching objectives' for sustainable development (UN 2002a).

\section{Too Hot To Handle?}

This decade of initiatives had placed the language of sustainable consumption firmly on the policy agenda. But agreement on what sustainable consumption is or should be about had proved remarkably difficult to negotiate (Manoochehri 2002). This failure to agree even on the domain of application of sustainable consumption is reflected in the multiplicity of definitions adopted by various institutions (Box 1).

\section{Box 1: Definitions of Sustainable Consumption}

The use of goods and services that respond to basic needs and bring a better quality of life, while minimizing the use of natural resources, toxic materials and emissions of waste and pollutants over the lifecycle, so as not to jeopardize the needs of future generations (Ofstad, 1994)

The special focus of sustainable consumption is on the economic activity of choosing, using, and disposing of goods and services and how this can be changed to bring social and environmental benefit. (IIED 1999)

Sustainable consumption means we have to use resources to meet our basic needs and not use resources in excess of what we need. (Participant definition, Kabelvåg, IIED 1998)

Sustainable consumption is not about consuming less, it is about consuming differently, consuming efficiently, and having an improved quality of life. (UNEP 1999)

Sustainable consumption is consumption that supports the ability of current and future generations to meet their material and other needs, without causing irreversible damage to the environment or loss of function in natural systems (OCSC 1999).

Sustainable consumption is an umbrella term that brings together a number of key issues, such as meeting needs, enhancing quality of life, improving efficiency, minimising waste, taking a lifecycle perspective and taking into account the equity dimension; integrating these components parts in the central question of how to provide the same or better services to meet the basic requirements of life and the aspiration for improvement, for both current and future generations, while continually reducing environmental damage and the risk to human health (UNEP 2001).

Two specific points are worth noting about this range of definitions. The first is that they take a variety of positions in relation to the question of how much emphasis should be placed on consumers, lifestyles and consumerism. Some definitions are very much more explicit that the domain of interest is related to the activity of consuming and the behaviours of consumers. Other definitions are vaguer on the boundaries between sustainable consumption and sustainable production. Others again are virtually indistinguishable from the Brundtland definition of sustainable development. 
A second, related point of variation between these definitions lies in the extent to which they imply consuming more efficiently, consuming more responsibly, or quite simply consuming less. Some definitions leave this question entirely unspecified. Some insist that sustainable consumption implies consuming less. Others assert that it does not mean consuming less.

The variability adopted with respect to these two key dimensions of the debate has served only to confuse matters in the decade since the Rio Summit. So much so, that by the time of the second Earth Summit in 2002, many of the organisations who had grasped the dialogue on sustainable consumption so enthusiastically began to distance themselves from its more radical implications. Some of them dropped it completely. In each case, the debates had generated a great deal of interest and enthusiasm. Experts had been brought together offering a range of potentially fruitful perspectives, aiming to come up with a solution; and then they had moved on or given up.

If there is an institutional consensus on sustainable consumption today, it is perhaps most aptly summed up by the UNEP definition in Box 1: sustainable consumption is not about consuming less, it is about consuming differently and consuming efficiently.

On the question of whether the focus of effort is to be placed on consumer behaviour and lifestyles or on the production of sustainable products, this statement is unhelpfully vague. In relation to the vexed question of whether to consume less or just differently it is uncompromising. Less consumption is not an option. Unfortunately, the combination of these two positions fails to advance the debate over lifestyle and consumerism at all, and leaves government policy-makers most likely to default to a position in which sustainable consumption means simply the consumption of more sustainable products. And the main mechanism for achieving this? The pursuit of resource productivity. Sustainable consumption is equivalent to sustainable production, under this view.

A similar emphasis can be found in the policies of the European Union. The environment directorate-general of the European Commission maintained a watching brief on sustainable consumption during the 1990s, with one staff member responsible part-time. But even this commitment was eliminated once the Commission had developed its White Paper on Integrated Product Policy - which was as close as it wanted to get to addressing consumption (Murphy, 2001). The UK sustainable development strategy has in its turn cast the debate mainly as a matter of consuming more sustainable products, and prioritised the pursuit of resource productivity in achieving this (PIU 2002, DEFRA 2003).

Far from cementing the focus on lifestyle issues inherent in Agenda 21, the WSSD Plan of Implementation (UN 2002b) appeared to retreat from the idea of lifestyle change. Instead, the focus in the Plan of Implementation was placed firmly on improvements in technology and the supply of more eco-efficient products, services and infrastructures. Once again, these actions are mainly about resource productivity of one kind and another, and typically collapse the distinction between sustainable production and sustainable consumption. 
So why precisely is the consumption side of the sustainable development debate so contentious? Why has mainstream policy been so reticent to follow up on the Rio commitment to lifestyle change? Is consumption just too hot to handle? Is it too complicated to understand? Or do those in positions of influence simply recognise that it is against their interests to carry the debate forward?

\section{The 'problem' with sustainable consumption}

At first sight it is difficult to unravel the confusion generated during the decade or so of debate on sustainable consumption. Some kind of insight can be gleaned however, from the way in which the issue of consumption entered the policy debate in the run-up to the Rio conference.

A part of the impetus for raising consumption as an issue in Agenda 21 came from the North-South dialogue that haunted the sustainable development debate both in the runup to and during the Rio summit. Countries in the North - principally the United States - routinely called for the need to address population growth (mainly in poorer countries) in order to curb environmental problems. Southern delegates tended to counter this pressure by pointing to consumption patterns in richer countries. Moreover, any attempt by the North to impose environmental controls on countries in the South was countered, understandably, by concerns that these would further reduce the limited consumption possibilities in poorer countries.

It was in the context of this heated debate that George Bush senior made his nowfamous remark that 'the American way of life is not negotiable.' This remark stands in sharp contrast to the stance of the newly-elected President Jimmy Carter in 1977, following the first oil price shock. He notoriously appeared on television wearing a cardigan, suggesting that Americans could save energy by wearing warmer clothing. It was a mistake not to be repeated by any self-respecting politician for some time afterwards.

In the light of these remarks, the outcome of the Rio debate was almost inevitable. Since the South would not agree to curtail population growth, the North could not contemplate curbing consumption and the South would not agree to curtail its consumption possibilities, the subsequent focus in the debate began to shift inexorably towards the less contentious issue of technological efficiency. ${ }^{1}$

These anecdotes hide three quite separate reasons why the debate on sustainable consumption has proved so problematic. The first reason has to do with the central role that consumption occupies within the conceptual basis of modern societies, particularly in the affluent North. In particular, this conceptual basis tends to adopt what we might call a supply chain view of well-being.

Paul Ehrlich (1968) was among the first to point out that environmental impact (I) can be characterised by the equation $\mathrm{I}=$ P.A.T, where $\mathrm{P}$ is population, $\mathrm{A}$ is the level of affluence and $\mathrm{T}$ is a factor related to the technological efficiency. 
A diagram similar to the one on the right appeared in the report of the second of the Norwegian Government workshops on sustainable consumption (IIED, 1999). It represents a conventional understanding of the relationship between consumption and human well-being in industrialised societies. Assuming that this supply chain view is accepted, it follows that the main aim of sustainable development strategies must be to maximise consumption while minimising waste and environmental damage - that is, to improve eco-efficiency.

\section{Figure 1: Supply chain view of well-being}

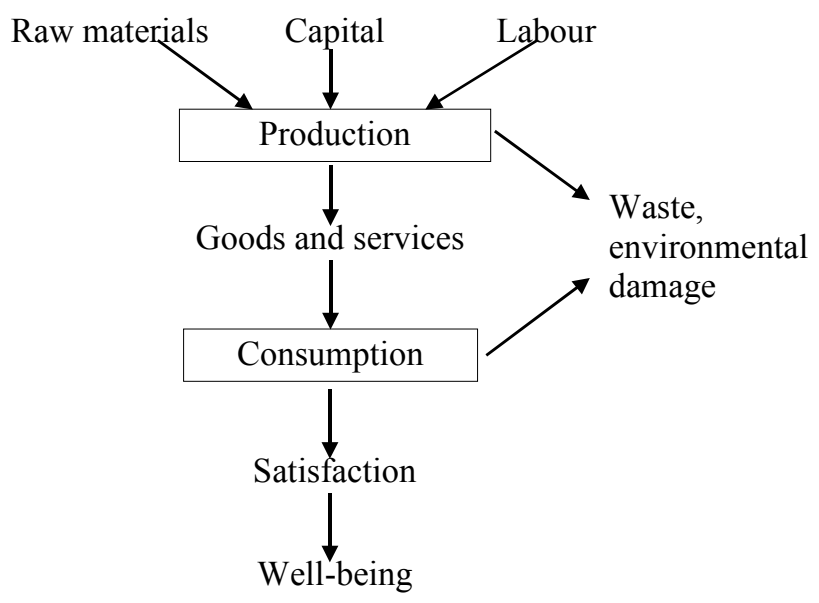

Part 3 of this report will explore and question the intellectual basis of this view in some depth. It is sufficient here to note only that, if the highest good is achieved by enabling people to consume, to consume more, and to increase their consumption options, then any questioning of the scale of consumption is bound to cause difficulties.

A further problem with the consumption issue is that it is an intimate, reflexive one. As soon as we start to question consumption, we are inevitably drawn towards an examination of our own individual consumption patterns. And as soon as we start to look at and question our own lifestyles, we are soon confronted with the challenge that change entails. Even if we are prepared to acknowledge that quality of life is not really about material consumption - as emphasised by many critiques of consumption (Kasser 2002) and in many traditional cultures (UNDP 1998) - we nonetheless come face-toface with a variety of obstacles to individual change. Again, the nature and extent of this challenge will be explored further in Part 3. Experiences of groups seeking to change their consumption will be described in Part 4.

A third difficulty is that changing consumption patterns appears to challenge vested interests. In particular, under current market conditions, it is almost impossible for businesses to engage seriously with any discussion about reducing levels of consumption. Whereas, in the early days of capitalism, corporate charters emphasised that companies existed to serve society, the rules of the market are now such that they must compete ruthlessly for survival. This is a vitally important issue for the sustainable consumption debate. We do not have time to explore it fully in the context of this report. However, it clearly informs some of our policy conclusions. 


\section{Taking up the challenge}

At this point in time, as we have shown, there remains a clear institutional resistance to taking up the challenge of sustainable consumption. But there are also a number of very good reasons doing so. These three reasons are, essentially, three distinct criticisms of conventional consumption patterns.

The first, and perhaps most widely accepted, criticism of consumption is a concern for inequality and the social and political tensions that arise from it. This concern is evident, for example, in the 1998 Human Development Report (UNDP 1998). It is also apparent in UNEP's global status report (UNEP 2002) which talks of the 'distorted' geography and demography of consumption (Figure 2).

Figure 2: Ratio of Consumption Levels, Industrialised and Developing Countries

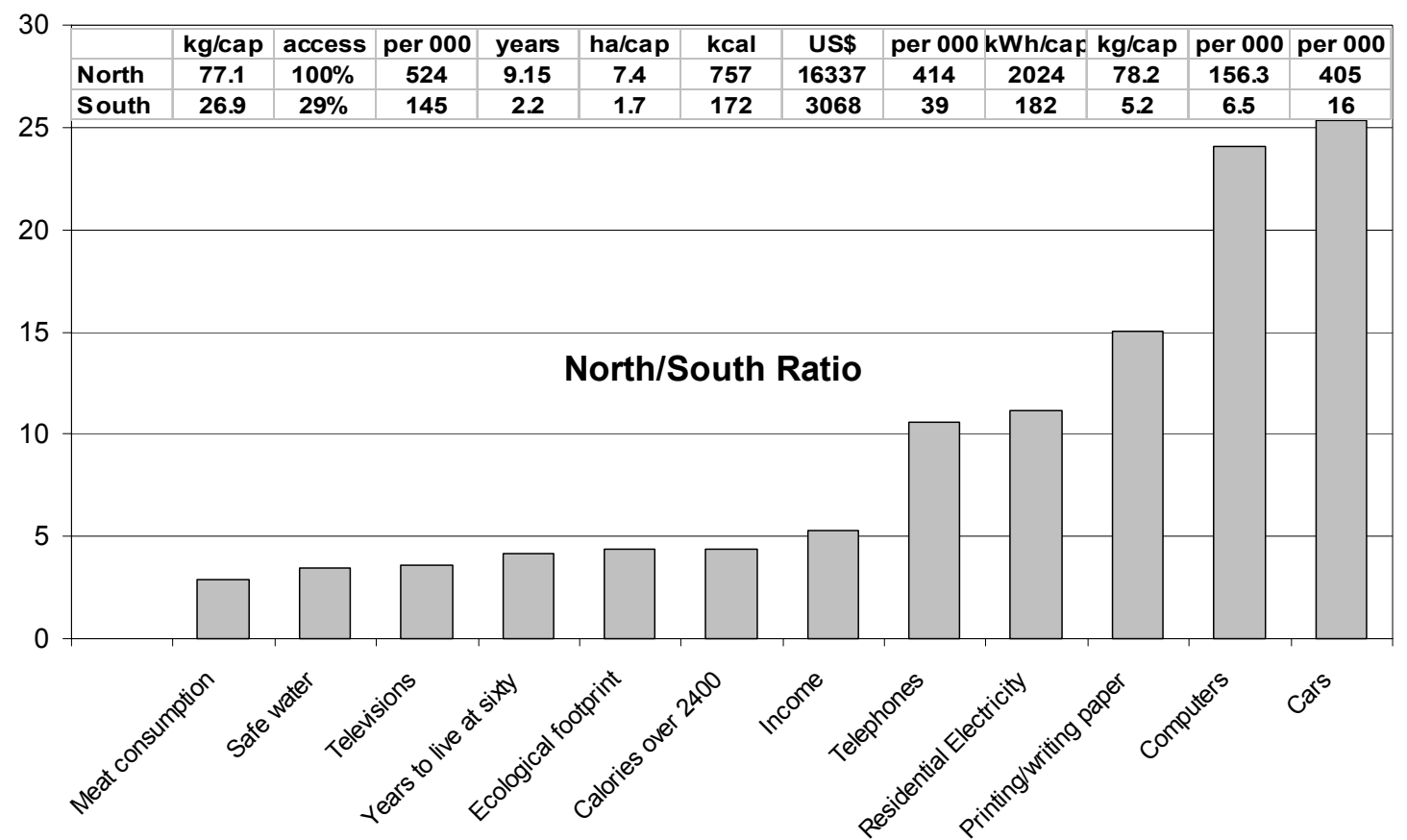

Sources: Ecological footprints: Wackernagel, 2000

Meat consumption: FAOSTAT, 2002

Electricity consumption: IEA, 1997

Other data: UNDP, 1998

The aggregate data hide huge variations. The wealthiest countries in the north enjoy per-capita income and consumption a hundred times as high as those of the poorest in the south. On the other hand, many residents of industrialised countries live in abject poverty (the "south in the north") and many in developing countries have high consumption lifestyles (the "north in the south").

Large differences in consumption level strike most people as unfair. Most cultures have strong moral injunctions for the rich to share with the poor (Michaelis 2000a). Yet bilateral aid flows have declined since Rio. The ideal of international redistribution of wealth remains deeply controversial. For much of the last 50 years, economists have 
espoused a 'trickle-down' theory, arguing that economic growth in rich countries contributes through trade to development in poorer countries. However, with the emergence of new growth theory, it is becoming clearer that free trade can enable the rich to get richer while the poor get poorer (Dosi et al., 1990). While over-consumption in the north may not be to blame for poverty in the south, both might be encouraged by trade policies.

A second reasons for taking up the challenge is that consumption is closely linked to environmental pressure and resource use (cf footnote 1). OECD (1998a) suggests that resource efficiency improvements are unlikely to be able to deliver the global factor of four-to-ten reductions in energy and material use that have been advocated as a condition for sustainability (von Weizsäcker et al., 1997).

One group of prominent environmental experts, the Factor $10 \mathrm{Club}$, has argued that a ten-fold increase in resource efficiency is needed over the next 30-50 years in industrialised countries if environmental pressures are to be held at a sustainable level. This factor ten improvement is based on the assumption that economic output will double in the period and yet the scale of energy and material use must be reduced by a factor of five.

Table 1: Historical increases in a range of productivity indicators (OECD, 1998)

\begin{tabular}{|l|l|l|l|c|}
\hline Sector/technology & Region & Productivity indicator & Period & $\begin{array}{c}\text { Annual } \\
\text { productivity } \\
\text { change (\%) }\end{array}$ \\
\hline Whole economy & 16 OECD countries & GDP/hours work & $1820-1992$ & +2.4 \\
\hline Whole economy & Japan & GDP/hours work & $1950-1973$ & +7.7 \\
\hline Whole economy & World & GDP/primary energy & $1971-1995$ & $+1.0 \%$ \\
\hline Whole economy & OECD & GDP/primary energy & $1971-1995$ & +1.27 \\
\hline Whole economy & United Kingdom & GDP/primary energy & $1890-1995$ & +0.9 \\
\hline Whole economy & China & GDP/primary energy & $1977-1995$ & +4.9 \\
\hline Whole economy & Japan & GDP/material use & $1975-1994$ & +2.0 \\
\hline Whole economy & USA & GDP/material use & $1975-1994$ & +2.5 \\
\hline Industry & OECD & Industrial production/energy & $1971-1995$ & +2.5 \\
\hline Industry & Industrial production/oil use & $1974-1986$ & +8.0 \\
\hline New cars/light trucks & USA & Vehicle fuel economy & $1972-1982$ & +7.0 \\
\hline New cars/light trucks & USA & Vehicle fuel economy & $1982-1992$ & +0.0 \\
\hline Commercial aviation & World & Tonne-km/energy & $1974-1988$ & +3.8 \\
\hline Commercial aviation & World & Tonne-km/energy & $1988-1995$ & +0.3 \\
\hline Commercial aviation & World & Tonne-km/labour & $1974-1995$ & +5.6 \\
\hline Telephone cables & Transatlantic & Telephone calls/mass & $1914-1994$ & +25.0 \\
\hline
\end{tabular}

Historical data (Table 1) suggest that high rates of productivity increase have been achieved in the past in particular sectors and in response to very strong incentives. But there is very little evidence to suggest that resource productivity improvements as high as $5-8 \%$ per year could be maintained throughout the industrial world over a period of 30-50 years, as required by the Factor 10 goal. From the labour productivity data we can see that it is possible to maintain rates of improvement of $2-3 \%$ per year over the 
long term. But we should bear in mind that labour is the largest single cost in the economy, and both workers and employers have strong incentives to increase its productivity. Massive shifts in policy would be required to provide the incentives needed for sustained resource efficiency improvements.

The third criticism of consumption is that current consumption patterns and trends are failing to contribute to an improvement in human well-being or flourishing. This criticism draws strength from a growing number of studies which find that people in industrialised countries do not feel any more happy or satisfied as average income grows beyond the level to meet basic physical needs. These observations connect the sustainable consumption debate with much broader questions about the direction of social, cultural and technological development, and our understanding of the Good Life and the Good Society. Some of these questions are discussed in more detail in Part 3 of this report.

Different participants in the sustainable development debate tend to place a different emphasis on each of these three criticisms of consumption. For example, the international development organisations (UNDP, DfID eg) place a high priority on the inequality critique. Environmental NGOs and international environmental policymakers tend to focus on the environmental critique. And social critics of modern society make much the failure of consumption to enhance human well-being.

The relative emphasis placed on each of these three criticisms also tends to influence the position taken with respect to the two key dimensions of the sustainable consumption definitions highlighted earlier. In particular, those concerned mainly with inequality tend to focus on consuming differently and the environmental groups favour consuming responsibly. More radical environmentalists and social critics emphasise the importance of remaining open to the possibility that we could live better by consuming less.

Recognising the diversity of positions in the debate, and their rootedness in fundamental values, is an important step in being able to carry the debate forward. Those holding different positions are unlikely to be able to convert each other. Progress may depend on finding pathways that can accommodate apparently conflicting viewpoints. Later in this report, we shall return to this point, and discuss in more depth its importance in moving towards policies for sustainable consumption.

For the moment, it is probably sufficient to note that whatever these differences of perspective, the question of consumption remains a vital one. During the same decade in which definitional disagreements dominated much of the debate, an increasing body of academic and policy opinion began to stress the urgency of the need to address consumption (Myers 1997, Crocker and Linden 1998, Jacobs and Røpke 1999, Princen et al 2002).

It may actually prove impossible to agree on a precise definition of sustainable consumption. This should not prevent us from addressing consumption itself. In particular, we find ourselves confronted by the very real need to ensure that environmental gains achieved through resource productivity are not offset by rebound effects, that entrenched behaviours do not render sustainable technologies redundant 
and that the continued expansion of consumer expectation and demand does not simply swamp the efficiency gains made through cleaner and more sustainable products.

Whatever perspective we end up taking on sustainable consumption, we are drawn inevitably towards the need for a clearer understanding of consumer behaviour and human choice. Why do we consume? What do we expect to gain from consumer goods? How successful are we in meeting those expectations? What constrains our choices? And what drives our expectations in the first place? All these questions become vitally important in the search for an understanding of consumer behaviour with which to inform sustainable development. The problem in addressing them lies, as we shall show in the next section, not so much in a dearth of potential models as in a superabundance of possibilities! 


\section{Understanding Consumption}

The terminology and the context of sustainable consumption are relatively recent. But the debate about sustainable consumption can only really be understood or evaluated in the context of much older and deeper debates about consumption, consumer behaviour and consumerism itself.

These wider debates have an extraordinary pedigree reaching back to classical philosophy and encompassing the critical social theory of the $19^{\text {th }}$ and early $20^{\text {th }}$ century, the consumer psychology and 'motivation research' of the early postwar years, the 'ecological humanism' of the 1960s and 1970s, the anthropology and social philosophy of the 1970s and 1980s, and the sociology of modernity, popularised in the 1990s. There is a sense, therefore, in which the debate on sustainable consumption, even if this fact is not always recognised by its protagonists, is a debate within a debate, a literature within a literature. Little wonder that it has proved so hard to agree upon!

Each of these different strands of thought was asking slightly different questions about consumer behaviour. The motivation researchers wanted to find out the best way to design and market products that people would buy; the critical social theorists and the humanists were alarmed at the ecological and social impacts of rampant materialism; the anthropologists and the sociologists were out to understand modernity, and reflect on the kind of society we had become. In spite of these differences, they all had something to say about consumption and about consumerism, and as such what they said is relevant to the aims of this report.

The purpose of this section is to provide an overview of this literature, and to draw out the key insights relevant to the debates on sustainable consumption. Starting with the model of rational choice implicit in conventional economics, the following sections go on to discuss some of the more sophisticated attempts to account for the variety and complexity of consumer behaviours. Further details and supporting accounts can be found in Bocock (1993), Edwards (2000), Jackson (2003), Michaelis (2000), Miller (1995), Røpke (1999) and Sanne (2002).

\section{Consumption as Well-being}

In some simple, rather straightforward sense, the consumption of goods and services may be seen as an attempt to provide for individual and collective well-being. This view of consumption is, in essence, the one encoded in conventional economics and policy. All transactions in the market are assumed to represent the rational choices of informed consumers. The consumer is visualised as a 'rational actor', attempting to maximise well-being or 'utility' within the constraints of the market, according to his or her own individual preferences.

This utilitarian model has become so widely accepted that most modern economic textbooks barely even discuss its origins or question its authenticity. Mas-Colell et al (1995), for example, assert that 'it is logical to take the assumption of preference maximisation as a primitive concept for the theory of consumer choice'. Begg et al (2003) simply 'assume that the consumer chooses the affordable bundle [of goods] that maximises his or her utility'. 
Economics itself tends to be silent, however, on the nature or origins of individual preferences. Consumer choice theory, after Samuelson (1938), has restricted itself essentially to deriving 'demand functions' for consumer goods on the basis of 'revealed preferences' in the market. The best we can say about consumer preferences according to this view is what we can infer about them from the patterns of expenditure on consumer goods in the market. If the demand for a particular brand of car or washingmachine or video-recorder is high, then we can infer that consumers, in general, prefer that brand over other brands. The reasons for this preference remain opaque within economics, as do the reasons for choosing cars, washing machines and video-recorders over, say, eco-tourism or leisure activities (Lancaster 1966, Schor 1992).

Implicit (and sometimes explicit) within the economic view is the assumption that human wants are essentially infinite. The desire for a particular commodity will eventually peak and decline; but the desire for commodities in general is taken to be insatiable. Some economists even adopt insatiability as the conceptual foundation for the 'economic problem': namely, the allocation of limited resources in the face of unlimited wants (Anderton 2000). In this way, the insatiability of consumer desire becomes a sort of ideological assumption at the heart of economics. What emerges from this assumption is the idea that the more we consume (in economic terms) the better off we are. Conversely, if the aim of society (and public policy) is to achieve continual improvement in well-being, then the appropriate way of achieving this is to pursue ever higher levels of (economic) consumption. This is the supply-chain view of well-being captured in Figure 1 above.

The equation of economic consumption with well-being goes a long way towards explaining the primacy of measures such as GDP in public policy terms (Jackson 2002a). It does not however, take us very far towards an understanding of the complexity of consumer motivations. Nor does it offer much that is new in the way of policies for sustainable consumption. The principal task for policy, under this view, is to ensure that the market is working efficiently, that external costs are internalised in resource prices, and that consumers have access to adequate information about their own consumption choices. These strategies are undoubtedly important. But they do not by any means exhaust the range of possible policy interventions suggested by a deeper understanding of consumer behaviour.

Ironically, practitioners in the field have been considerably more inquisitive about the nature and origins of consumer motivations than economic theorists. New areas of inquiry such as consumer psychology, marketing and 'motivation research' have developed a rather rich body of knowledge - a 'science of desire' (Dichter 1964) - for producers, retailers, marketers and advertisers wanting to know how to design and sell products that consumers will buy. Little if any of this research concerns itself explicitly with the environmental or social impacts of consumption. But its insights are crucial to a proper understanding consumer behaviour. Much of the inspiration for this body of research is drawn from outside economics, in disciplines such as humanistic psychology, sociobiology and anthropology. Since these fields are discussed in more detail below, we defer discussion of certain key insights from consumer research to subsequent sections. 


\section{Consumption and Human Needs}

In contrast to the economic view, there is a view of human motivation that attempts to relate well-being to the satisfaction of human needs. This view is important to an understanding of consumer behaviour because it provides a very specific theory about the motivations that underlie consumer choice. In one sense, this view can be seen as a variation on the 'rational choice' model. The rational consumer is one who chooses the consumption goods that best satisfy his or her needs. The pursuit of well-being becomes a search for better and better ways of satisfying individual and collective needs. At the same time, the needs-based approach to consumer behaviour is far from being just a variation of the economic model. In fact, it has provided the foundation for a potentially far-reaching critique of that model.

This critique has its origins in the extended debates over industrial development that occupied social commentators from the late $18^{\text {th }}$ Century onwards (Springborg 1981). Rousseau articulated a distinction between natural or 'true' needs and false ones. He regarded the latter as having been created artificially to serve the interests of industrialisation. The distinction was echoed in the writings of Marx (1859) and inherent in the later work of Marcuse (1969), Fromm (1976) and Illich (1977). The general thrust of these critiques was an attempt to undermine the legitimacy of industrial society's claim to provide for individual and social well-being. Though it had generated a whole new sets of false needs, argued these commentators, industrialisation had failed to meet the 'true' needs of the population.

Partly because of the critical nature of this discourse, modern economics has been wary of the terminology of needs, preferring instead to cash out consumer choice in terms of wants, desires and preferences. Some economists argue that needs are irrelevant for economics. Even Galbraith's eloquent challenge to the 'affluent society' is couched in terms of wants rather than needs, because of economic sensitivity to the language of needs. Nonetheless, his intention to undermine the economists' insatiability premise is quite clear. 'The notion that wants do not become less urgent the more amply the individual is supplied,' writes Galbraith (1958), 'is broadly repugnant to common sense.'

A similar argument was made by Fromm (1976) who pointed to an essential distinction, present in the writings of all those concerned with human well-being. On the one hand, there were 'desires which are only subjectively felt and whose satisfaction leads to momentary pleasure'. On the other hand there were 'objectively valid needs' which are 'rooted in human nature and whose realisation is conducive to human growth'. While the former may be regarded as insatiable, the latter are not, Fromm argued.

The needs-based critique of conventional development has drawn considerable strength from the development of humanistic psychology. In Motivation and Personality, Maslow (1954) put forward a model of human motivation which is based explicitly on a finite set of universal human needs. Maslow categorised these needs in terms of material needs (for subsistence, security and protection), social needs (for status, selfesteem and belongingness) and 'growth' needs (such as truth, understanding, aesthetics, justice, and meaning). 


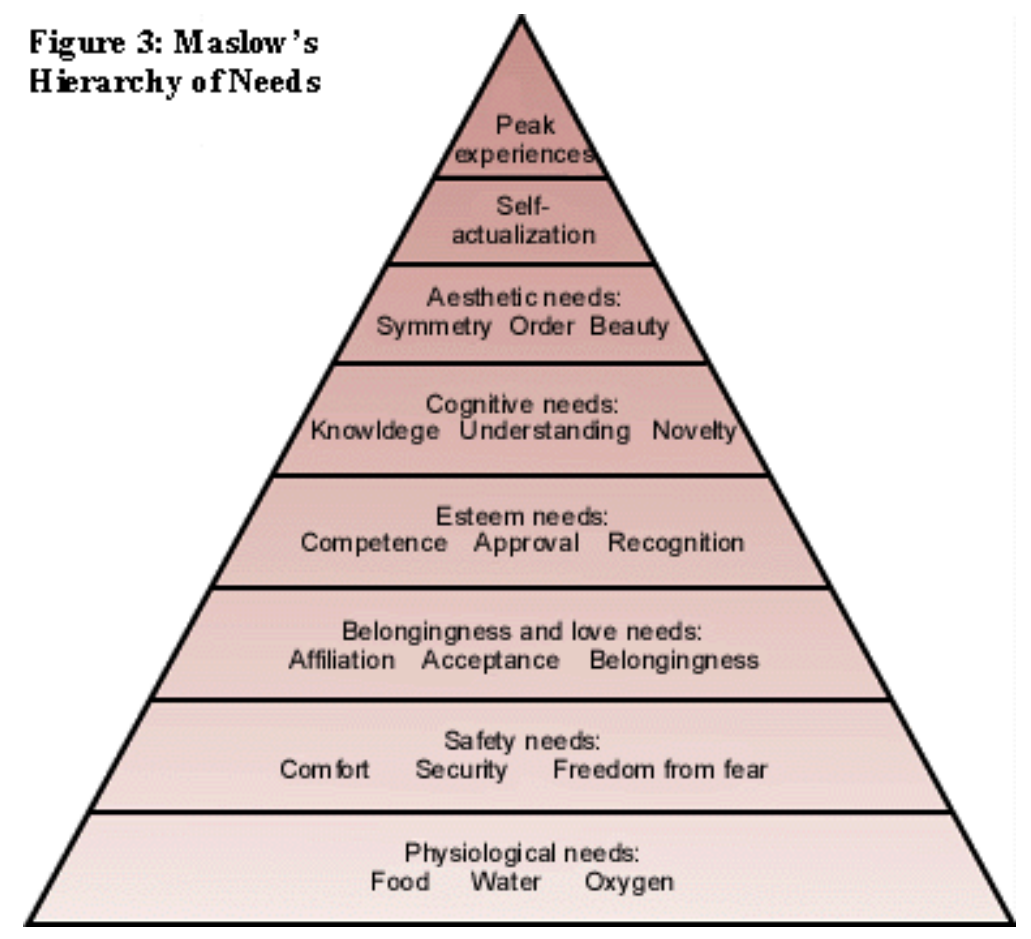

In his early writings, Maslow pictured these needs as a hierarchy (Figure 3, left) with material needs at the bottom, social needs in the middle and growth needs at the top. He argued that, generally speaking, human development proceeded by satisfying the lower (material) needs first, and that only after these were met, would 'higher' needs become relevant. The hierarchical nature of this framework has been criticised widely (Douglas et al 1998). In fact, Maslow (1968) himself abandoned the hierarchy in later work and placed material and higher needs side-by-side in recognition of what he called a 'duality' in human nature.

Maslow's work has been enormously influential in a number of areas, not least in consumer research, where it is quite common to find reference to the needs hierarchy (Kassarjian and Robertson $1968 \mathrm{eg}$ ). Thanks to Maslow, designers, manufacturers and retailers have long been fluent in the discourse of needs, as a means of persuading potential consumers of the benefits of their products and services.

More recently, Maslow has also provided the inspiration for a variety of modern attempts to provide a needs-based account of human behaviour and development (Doyal and Gough 1991, Mallmann 1980, Max Neef 1991). These theories all share with Maslow the idea that it is possible to identify a finite set of universal human needs. They also all tend to articulate an important distinction between needs and 'satisfiers'. Needs are finite, few and universal. Satisfiers - the means chosen to meet the underlying needs - are potentially infinite and depend on a variety of personal, social and cultural choices.

This recognition gives rise to a linguistically confusing, but potentially far-reaching insight into consumer satisfaction, namely that not all our attempts to meet our underlying needs are equally successful. Not all 'satisfiers' actually satisfy! Max Neef (1991) sets out a typology of 'satisfiers' to reflect this complexity. His typology ranges from synergistic satisfiers (things which are very good at satisfying multiple needs in concert) to pseudo-satisfiers (things which appear to offer satisfaction of a particular need but actually fail to do so) and violators (things that actually prevent the satisfaction of the need they were intended to meet).

At one level, this kind of distinction reflects common wisdom about the nature of consumer satisfaction. For example, we realise that certain kinds of food are better 
nutritionally than others in meeting physiological needs; that, even though we crave them, some foods are bad for our health; and that - at a certain level of intake - more food may actually be worse for us than less. We are familiar with the fact that certain kinds of consumer addictions contribute to neither our physical nor our psychological well-being. We accept that certain purchases do not always match up to our prepurchase expectations. Many will recognise the phenomenon of 'post-purchase dissonance' - when the satisfaction we expected to receive from a particular purchase evaporates and we are confronted instead with disillusionment and a sense of confusion at having made the purchase. The idea of pseudo-satisfaction is a way of encapsulating these kinds of phenomena.

Needs-based arguments have been attacked for being unnecessary, naïve and moralistic (Baudrillard 1970, Douglas et al 1998, Heyne 1983). Nonetheless, the distinction between physiological needs and social or psychological needs is a potentially valuable one; as is the distinction between different kinds of satisfiers. As we shall see in the next section, these two distinctions appear to offer considerable promise in the project of developing more sustainable consumption patterns. Moreover, the concept of needs has been indelibly encoded in the discourse of sustainable development, ever since the Brundtland definition (WCED 1987). It would seem judicious, therefore, not to reject the needs-theoretic approach outright.

\section{Consumerism as a Social and Psychological Pathology}

The distinction between true and false satisfiers is reminiscent of the distinction between true and false needs proposed by the critical theorists; and it serves a very similar function in critiquing modern consumer society. Specifically, it seems to suggest that some at least of our consumer choices are less than successful in meeting our needs. Some of what we consume does us little or no good. Consumption is not geared unfailingly towards increasing our well-being and improving our quality of life as economics would have it. Some of it appears to impede well-being and decrease our quality of life.

This kind of claim has occupied a central role in critiques of society for well over two centuries. Even in the $17^{\text {th }}$ Century the political philosopher Thomas Hobbes noted the 'pervasive anxiety' of a society increasingly given over to materialistic values. In the $19^{\text {th }}$ Century, Marx decried the 'fetishism of commodities' that characterised capitalist society. On the cusp of the $20^{\text {th }}$ Century, Thorstein Veblen contrasted the 'destructive traits' of the 'pecuniary culture' with the 'industrial virtues' of earlier times. He coined the now-familiar term conspicuous consumption to denote what he referred to as the 'invidious' social comparison driving consumer behaviour among the American upper middle classes.

In the space of a century, the 'pecuniary culture' may have established an iron grip on modern social mores. But it has also generated a host of other critics. Writing in the early sixties, Lewis Herber (1963) argued that human society had 'reached a level of anonymity, social atomisation and spiritual isolation... virtually unprecedented in human history'. Erich Fromm (1976) was alarmed at the alienation and passivity which pervaded modern life, and placed the blame squarely on an economic system predicated on increasing levels of consumption. In attempting to discover why 'unprecedented and 
fast-moving prosperity had left its beneficiaries unsatisfied', Tibor Scitovsky (1976) highlighted the addictive nature of consumer behaviour, and its failure to mirror the complexity of human motivation and experience. Ivan Illich (1977) attacked the ideology that equates progress with affluence and needs with commodities.

These critics have to some extent been supported by empirical evidence. In The Joyless Economy, Scitovsky could already cite the failure of reported levels of well-being to match the growth in GDP (Scitovsky 1976). In 1991, Erik Jacobs and Robert Worcester found that people were marginally less happy than they had been in 1981 in spite of considerably increased personal income (Worcester 1998). A similar result was reported over a longer period by Myers and Diener (1996). Oswald (1997) has found that reported levels of 'satisfaction with life' were only marginally higher than they had been in the mid-seventies. In some countries, including Britain, they were actually lower. By a perverse contrast, some studies of human happiness reveal that some of the poorest countries - Bangladesh, Azerbaijan, Nigeria for example - are amongst the happiest in the world (Worcester 1998).

Most recently, Kasser (2002) has marshalled an impressive body of evidence to the effect that materialism commands a high price in terms of individual well-being. Those who are motivated by materialistic values, claims Kasser, score consistently lower in measures of life-satisfaction than those who are not. Kasser's explanation for these differences calls explicitly on the theory of needs. Material commodities are effective satisfiers for material (physiological) needs. They appear to be much poorer satisfiers of our psychological and social needs. The more we attempt to pursue the satisfaction of these latter needs through materialistic means, the less effectively we satisfy them. That at least is the claim made by Kasser and many of his predecessors.

If this critique is right, western consumerism appears determined to pursue a way of life that offers neither psychological nor social satisfaction. To make matters worse, it also has profound environmental impacts. In pursuit of an unapproachable concept of wellbeing, we are not only failing to meet our own social and psychological needs, we are also damaging the environment. As Paul Wachtel (1989) comments in The Poverty of Affluence, the 'consumer way of life is deeply flawed, both psychologically and ecologically'.

That environmental damage turned out to be the price we had to pay to improve human well-being would be unfortunate. That environmental damage is a side-effect from a failed attempt to improve human well-being is potentially tragic. Consumer society, in this view, appears to be in the grip of a social or psychological pathology.

On the other hand, if this critique is right, it also appears to point to an avenue of hope. Environmental imperatives - the demand to reduce the material impact of human activities - are often portrayed and often perceived as constraining human well-being and threatening our quality of life. In contrast, the combined 'consumption as pathology' critique suggests that existing patterns of consumption already threaten our quality of life, not just because of their impact on the environment, but also because of their failure to satisfy our social and psychological needs. Reducing the material profligacy of our lives, on this view, will not only help the environment, it will also improve the quality of lives. As Levett et al (2003) have pointed out in a recent report 
to the Sustainable Development Commission, a less materialistic society has the potential to offer consumers $A$ Better Choice of Choice.

However, this entire critique begs a number of crucial questions. Why, if the consumer society fails to satisfy, do we continue to consume? Is there a pathological aspect to consumer behaviour? If there is, what is the nature of the pathology? If not, why does consumerism have such a grip on us? And perhaps most importantly of all, what could we possibly do to release ourselves from that grip?

The subsequent sections all address these questions in one way or another. Not all of them agree on the nature or even on the existence of a consumer pathology. Yet they all contribute some understanding towards the strength of our ties to consumerism. And some of them, at least, offer the potential to redirect consumer society towards a most sustainable path.

\section{Consumption as an Evolutionary Adaptation}

If needs theory provides little understanding as to why consumerism should prove so seductive, evolutionary psychology offers the insight that seduction is precisely the point!

The social psychologist William McDougall (1908) was amongst the first to suggest that human beings possess what he called an 'instinct of acquisition'; in other words that we consume in response to evolved behaviour patterns, over which we have little or no individual or social control. The simplistic idea that human beings are driven by a universal biological instinct to acquire material goods is problematic. As Dittmar (1992) points out, such an instinct could not account for the huge differences in 'materiality' between cultures. Nor could it account for differences in the same culture over time. However, modern variations on the evolutionary theme are considerably more sophisticated than McDougall's early suggestion, and deserve some consideration.

The foundation for an evolutionary view of human motivations was laid down by Darwin himself. In the final chapter of On the Origin of Species he suggested that 'in the distant future' the study of human psychology would be based on an evolutionary understanding (Darwin 1859). He himself ventured some way towards this project in The Descent of Man (Darwin 1871) where he set out the notion of sexual selection, namely: that evolutionary adaptations were selected, in part, according to their success in attracting sexual mates. In The Expression of the Emotions in Man and Animals (1872) he posited that the development of emotions was itself an example of an evolutionary adaptation.

It is only a small step from these two insights to suggest that the form and expression of human emotional and behavioural characteristics are determined in no small part by their success as evolutionary adaptations. In the hands of a whole new generation of biologists and psychologists these insights have become a new and powerful theory about human nature (Cronin 1991, Miller 2000, Ridley 1994, Wright 1994). The complex ramifications of evolutionary psychology need not concern us here. But a general understanding of its implications does turn out to be highly relevant to the question of consumer behaviour (Jackson 2002b). 
Ridley (1994) sets out the evolutionary psychology stall persuasively. Human nature, he argues, is fundamentally influenced by the strategies and ploys of what Dawkins (1976) called the 'selfish gene'. By definition, those genes which have survived so far are those which convey traits and characteristics that are conducive to survival - or to be more precise: characteristics that would have been conducive to genetic succession in the ancestral environment (Tooby and Cosmides 1990). In particular, evolutionary forces have conditioned us continually to strive to position ourselves in relation to the opposite sex and with respect to our sexual competitors.

Moreover, this fundamental element of sexual competition never abates, according to evolutionary psychology. Rather, we find ourselves conditioned to run faster and faster as time goes by, like the Red Queen in Lewis Carroll's Alice in Wonderland, precisely because our competitors are all engaged in the same unending struggle. As a (male) reviewer of Ridley's book noted with some glee: 'animals and plants invented sex to fend off parasitic infection. Now look where it has got us. Men want BMWs, power and money in order to pair-bond with women who are blonde, youthful and narrowwaisted'!

The idea that consumption may have something to do with sex has a clear resonance with common wisdom. Advertisers and media executives have developed an extraordinary creativity in using sex and sexual imagery to sell their products. There is plenty of evidence to suggest that consumers themselves relate both the activity of shopping and the products they shop for, either implicitly or explicitly to sexual motivations (Falk and Campbell 1997, Rosenblatt 1999). In a very recent paper entitled The Fires of Desire, the veteran consumer researcher Russell Belk and his coauthors conducted a cross-cultural survey in which they tested the hypothesis that desire plays a vital role in shaping and motivating consumer behaviour (Belk et al 2003). In all three of the cultures examined, the authors found that consumer motivations were (often inextricably) entwined in the language and imagery of sexual desire.

It is important to note that not all of the behaviours that emerge from evolutionary psychology are self-serving, sexually-aggressive behaviours. The theory also offers an account of moral, social and altruistic behaviours. Key theories in evolutionary psychology suggest that such behaviours evolved in humans precisely because they offer selective advantages (Wright 1994). There is also an important body of work which shows how the individual choice between competitive behaviour and cooperative behaviour depends crucially on the social and institutional context. Axelrod (1984) showed how a conditional form of altruism could flourish even in competitive societies. In very competitive societies, self-serving behaviour tends to be more successful than altruism. But in a society characterised by cooperation, socially responsive behaviour tends to be favoured over competition.

Some clear policy lessons emerge from all this. Firstly, of course, evolutionary psychology points to the limitations of appealing to the 'better nature' of consumers. Exhortations to individual restraint are likely to be meet with limited success, particularly where social conditions militate against altruistic behaviour. Conversely, this perspective highlights the crucial importance of the social and cultural context in shaping and constraining individual choice. Evolutionary psychology may offer a view of human nature in which, in Dawkins' words, 'sustainability doesn't come naturally' 
(Dawkins 2001). But it also highlights the importance of policy intervention to nurture, support and sustain moral and social behaviours.

\section{Display Consumption and Status-Seeking}

Amongst the behaviours suggested by the evolutionary psychology of consumerism are those concerned with display and status. We have already drawn attention to some of these behaviours. Veblen highlighted the 'invidious' nature of social comparison, and was derogatory of the culture that encourages it. Preferring to condemn than to condone, Veblen offered little in the way of understanding of the underlying motivations for consumer behaviour. Evolutionary psychology, on the other hand, clearly has something to offer here. Specifically, the arguments from sexual selection suggest that at least some 'conspicuous' consumer behaviours occupy the role of sexual display. That is, they advertise availability, fertility, potency, fidelity and a variety of other characteristics desirable to the opposite sex.

Display consumption is not limited to sexual display, however. Other kinds of display speak less directly to sexual availability, but represent a means of establishing social position within status hierarchies. The notion of a status hierarchy is an important one in evolutionary psychology. It is derived from earlier work by the Norwegian biologist Schjelderup-Ebbe on the now-familiar concept of a 'pecking order'. According to evolutionary psychology, status hierarchies play a rather complex but extremely important role in the social organisation that controls both rights and access to resources. High positions in the hierarchy - according to the theory - correspond to improved access, not only to financial or physical resources, but also to sexual resources (potential mates), to social resources (friends, family, community) and to information vital in its turn to protect the long-term social interests of the individual and his or her progeny. This latter view is reinforced, as we shall see below, by research from social anthropology.

The more general notion that certain kinds of consumption are used to advertise status, power and social position has been explored extensively in the sociological discourse on consumption. Following Veblen's work, the French sociologist Pierre Bourdieu (1984) has suggested that patterns of consumer behaviour provide the mechanism for defining and maintaining class distinctions in modern society. A more general variation on this idea provided by Fred Hirsch's concept of positional consumption.

Hirsch (1977) suggested that once our material needs are met, we are led to consume 'positional goods', goods that have the characteristic of allowing us to 'position' ourselves socially with respect to our fellows. The defining quality of such goods is their social scarcity; and it is this scarcity that provides the vehicle for social positioning. If the goods were freely available, their value in positioning us in relation to our fellows would be diminished. Once enough people possess these goods, moreover, their value in positioning us ahead of the crowd declines, and those wishing to stay ahead must engage in a search for new goods with social scarcity.

In this way, Hirsch argues, the positional economy engages us in a never-ending struggle - reminiscent of the Red Queen argument of evolutionary psychology. 'It is a case of everyone in the crowd standing on tiptoe and no-one getting a better view,' he 
suggests (Hirsch 1977, 49). At the start of such a process, a few individuals gain a better view by standing on tiptoe. But the upshot is that others are forced to follow just so that they can maintain their original position. However, 'if all do follow... everyone expends more resources and ends up with the same position'. The vigorous pursuit of positional consumption, according to Hirsch, turns out to be nothing more than a kind of 'zero sum game'.

Given the apparent futility of this Red Queen race, it is tempting to label all such behaviours as either pathological or morally reprehensible. This rebuke has certainly been implicit (and sometimes explicit) in the writings of social theorists like Veblen, Hirsch and Bourdieu. Evolutionary psychology, however, appears to have turned the moral concern of social commentators on its head by offering an evolutionary 'legitimation' for display consumption. From this perspective, status-seeking consumer behaviour cannot be regarded as either irrational or pathological - at least from an individual point of view. Rather, it is an expression of behavioural traits that have been successful in ensuring the survival of the species for generations.

There are some very good arguments, as we shall see below, for not taking this 'legitimation' too seriously. On the other, this should not discourage us from acknowledging the importance of status-seeking behaviours to an understanding of consumer motivation. Nor should it stop us using that understanding to inform sustainable consumption policies. Some interesting suggestions along these lines have already been made. A recent report to the Prime Minister's Strategy Unit, for example, has suggested the idea of taxing positional goods (Donovan et al 2002).

\section{'Ordinary' Consumption and Consumer 'Lock-in'}

Display consumption - sometimes called 'Veblenesque' consumption - has occupied a central role in many of the sociological debates on consumption over the last century. Recently, however, the emphasis on this aspect of consumer behaviour has itself been criticised. A handful of writers have argued that a great deal of consumption in fact takes place inconspicuously as a part of the ordinary, everyday decision-making of millions of individual consumers. 'Ordinary' consumption, argue these authors, is not oriented particularly towards individual display. Rather it is about convenience, habit, practice, and individual responses to social norms and institutional contexts (Shove and Warde 1997, Groncow and Warde 2001).

The concept of 'inconspicuous consumption' is important to an understanding of consumer behaviour for several reasons. In particular, it has a clear resonance with our day-to-day experience of consuming. High-street shopping for fashion goods may explicitly engage our display motivations on selected occasions. Apart from compulsive or addictive shoppers however, we do not as a rule spend our day-to-day life engaged consciously in this kind of consumption. Much everyday consumption is almost invisible, even to ourselves.

In particular, the regular payments that leave our bank accounts to cover our mortgages, insurance payments, utility bills and local taxes appear to have very little in the way of display or status associated with them at all. Even when we change electricity or gas suppliers, for example, very few people tend to be motivated in their choice of new 
supplier by any attempt to improve their social standing. Indeed there would be little point in engaging in such a strategy. As well as being inconspicuous to ourselves, such choices are virtually invisible to our social peers, our sexual competitors, or the world at large.

A closer examination reveals that some at least of our 'ordinary' consumption conceals important display and status aspects. In particular, of course, many everyday household consumption decisions are shaped by a single and very significant consumption decision with clear display and status connotations: namely, our choice of dwelling. A larger house in a better neighbourhood may offer social and personal advantages to its owner or tenant. It also entails larger mortgage (or rent) payments, higher utility bills, larger council taxes, heavier insurance premiums and a greater demand for furniture and fittings. Having made the 'critical' consumption choice of house-purchase (or rental), we may then find ourselves locked into a variety of other consumption decisions which have little or nothing to do directly with status. Nonetheless, the status component in such decisions is difficult to deny.

It is clear, however, that critical consumption decisions - such as house or vehicle purchase - are only one of many components that influence everyday consumer choice. A key lesson from the literature on ordinary consumption is that these day-to-day choices are constrained within a rather complex decision architecture, which includes historical, social, institutional and even political components.

To take one simple and rather familiar example, the fuel consumption associated with heating our home is determined (amongst other things) by the available fuel supply, the efficiency of the conversion devices, the effectiveness of thermal insulation in the dwelling, and the level of thermal comfort programmed into our thermostats. These factors in their turn are constrained by the historical development of the fuel supply and appliance industries, the institutional design of the energy service market, the social norms associated with personal convenience and thermal comfort, and our own personal responses to those norms. The process of socialisation of these norms is itself complex one, often involving incremental changes over long historical periods (Shove 2003). Typically, at the point of everyday decision, the ordinary consumer will have little or no control over most of this decision architecture.

The message that flows from this analysis, therefore, is that consumers are a long way from being willing actors in the consumption process, capable of exercising either rational or irrational choice in the satisfaction of their own needs and desires. More often they find themselves 'locked in' to unsustainable patterns of consumption, either by social norms which lie beyond individual control, or else by the constraints of the institutional context within which individual choice is executed.

Emphasising that these circumstances are 'often deliberately created by producer and business interests' (Sanne 2002, 286), proponents of this view have something in common with the critical social theory of Bourdieu and others. They also offer some support to the idea that consumer society is suffering from some kind of social pathology. 
However, the later writers locate the pathology in a different place than the earlier social critics do. Specifically, they claim, this pathology does not reside within the remit or control of the individual consumer. Nor is it some disembodied feature of 'consumer culture' Rather it is to be located quite specifically within the institutional architecture of everyday choice. The implications of this position for sustainable consumption policy are profound. In particular, it suggests the need, once again, for a very close attention to the institutional and social context within which consumer behaviour is shaped and constrained.

\section{The Symbolic Role of Consumer Goods}

Proponents of 'ordinary consumption' down-play the importance of Veblenesque explanations about consumer behaviour. But there is one underlying feature of display consumption which is scarcely deniable and which has much wider connotations than its application to status-seeking behaviours. This is the insight that, in addition to their purely functional characteristics, material commodities possess vitally important symbolic properties.

Once again this idea has some resonance with popular psychology about our relationship with material objects. A child's first teddy bear, a woman's wedding dress, the club shirt of the football fan, the torn and frayed photograph of an old friend, the stamp collector's prized first-day cover, the very latest chart CD, this year's executive toy, the souped-up, low-sprung sports car of the 'boy-racer': all these examples suggest that there is much more at stake in the possession of material artefacts than simple functional value.

Over the second half of the $20^{\text {th }}$ Century, the insight that consumer goods possess symbolic properties has become an increasingly important defining feature of sociological debates about consumption. The hypothesis itself has arisen from the confluence of some rather diverse intellectual influences including the semiotics of Charles Morris (1946), the structuralism of Roland Barthes (1966), the social philosophy of Baudrillard $(1968,1970)$, the social anthropology of Marshall Sahlins (1976) and Mary Douglas (1976), and the consumer and motivation research of Ernest Dichter (1964), Elizabeth Hirschmann and Morris Holbrook (1980), Russell Belk (1988) and others.

Again it would be impossible to do justice to this enormous literature here. Nonetheless, the most important lesson from this huge body of work is very clear. Material commodities are important to us, not just for what they do, but for what they signify: about us, about our lives, our loves, our desires, about our successes and failings, about our hopes and our dreams. Material goods are not just artefacts. Nor do they offer purely functional benefits. They derive their importance, in part at least, from their symbolic role in mediating and communicating personal, social, and cultural meaning not only to others but also to ourselves.

The explanatory power of this hypothesis is high. In particular, it offers a vital clue to our understanding of social and psychological needs. Indeed, it suggests that material artefacts may after all be legitimate candidates in the search for satisfaction of these needs, precisely because of their ability to embody symbolic meaning. What looked 
like irrational or pathological consumer behaviours become increasingly comprehensible once we accept that material objects are signs. 'Forget the idea of consumer irrationality,' urge Mary Douglas and Baron Isherwood in The World of Goods. 'Forget that commodities are good for eating, clothing and shelter; forget their usefulness and try instead the idea that commodities are good for thinking; treat them as a nonverbal medium for the human creative faculty' (Douglas and Isherwood 1979).

The implications of this hypothesis for the project of sustainable consumption have barely yet been tested. Typically, proponents of this view have restricted themselves to rejecting the needs-based 'double dividend' as a fantasy and chastising the humanistic critique of consumer society as a 'naïve and absurd moralism' (Baudrillard 1968). In our view, this rejection is premature. Later in this paper we shall explore the policy ramifications of the idea that material objects possess symbolic value. In the intervening sections, we explore some specific aspects of the symbolic role for consumer goods.

\title{
Consumption and the Extended Self
}

One of the most obvious applications of the broad thesis that goods are signs, lies in the role of material commodities in constructing and maintaining personal identity. The idea that we tend to regard possessions as parts of ourselves dates back (at least) to the philosopher William James who argued that:

\begin{abstract}
'A man's Self is the sum total of all that he can call his, not only his body and his psychic powers, but his clothes and his house, his wife and his children, his ancestors and friends, his reputation and works, his lands, and yacht, and bank-account. All these things give him the same emotions. If they wax and prosper, he feels triumphant; if they dwindle and die away, he feels cast down - not necessarily in the same degree for each thing, but in much the same way for all.’ (James 1890, 291-292)
\end{abstract}

The implications of James's observation for consumer behaviour have been explored in considerable depth in consumer research and of course employed widely in advertising and marketing consumer goods (Haire 1950, Fine and Leopold 1993).

In a detailed survey of the relationship between possessions and the 'extended self' Russell Belk (1988) explores the functions of possessions at different stages of human development, from their role in enabling the infant to distinguish between self and environment to their function in achieving a sense of continuity and preparing for death in later life. He also undertakes a comprehensive survey of the various psychological and social processes whereby consumer possessions are 'cathected' or incorporated into the extended self.

There are few places where this process is more naked to the popular scrutiny than in the case of the automobile, which has long been recognised as far more than a means of getting from one place to another. In spite of an equally popular disdain for the fact cars have come to symbolise (for their owners at least) a wide variety of cultural goods: social status, sexual prowess, personal power, freedom, and creativity (Freund and Martin 1994, Haggett 2000). Like many other material artefacts, they are now deeply imbued with cultural meaning. The following anecdote from New York columnist Benjamin Stein makes the point entertainingly: 
Sometimes I test myself. We have an ancient, battered Peugeot, and I drive it for a week. It rarely breaks, and it gets great mileage. But when I pull up next to a beautiful woman, I am still the geek with the glasses. Then I get back into the Porsche. It roars and it tugs to get moving. It accelerates even going uphill at $80 \ldots$ It makes me feel like a tomcat on the prowl.. with the girls I shall never see again pulling up next to me, giving the car a once-over, and looking at me as if I were a cool guy, not a worried, over-extended, 40-year-old schnook writer (Stein 1995).

This example carries echoes of earlier discussions about display consumption and the insights from evolutionary psychology. It is, in part at least, the symbolic character of material goods that facilitates their role as status signifiers. However, the symbolic importance of possessions is not simply about status. Nor is it solely confined to questions of individual identity. The individual psychology of material possessions is important, of course. But the task of constructing and maintaining symbolic identity is fundamentally a social one.

\section{Consumer Goods and Social Identity}

Symbols are by their nature socially constructed. The value attached to symbols is constantly negotiated and re-negotiated through social interactions within a specific cultural context. For a symbol to serve its purpose of conveying social meaning, as Hirschman (1980) explains, 'there must be at least two parties - the symbol possessor (perhaps a consumer desiring to express his/her identity to others via a display of symbols) and the symbol observer (perhaps another individual to whom the consumer wishes to communicate his/her identity).

In the hands of certain sociologists and social philosophers, this insight has become the basis for a quite specific view of consumer society. According to this view, the individual consumer is locked into a continual process of constructing and reconstructing personal identity in the context of a continually renegotiated universe of social and cultural symbols. The principal object of consumption in the consumer society is not, according to Baudrillard (1970), material goods or even economic value, but signs, symbolic value.

Baumann (1998) points to the convenient resonances between this process of perpetual reconstruction of identity, and the impermanent, transient nature of modern consumer goods. 'Aggregate identities, loosely arranged of the purchasable, not-too-lasting, easily detachable and utterly replaceable tokens currently available in the shops,' he writes, 'Seem to be exactly what one needs to meet the challenges of contemporary living.' A similar thesis is advanced in Lewis and Bridger's (2001) book The Soul of the New Consumer.

There is a sense in which this model of the perpetual reconstruction of social identity through material goods appears to reinforce the idea that consumer society is in the grip of some kind of social pathology. However, as some of the proponents of this view are keen to point out, this is not a pathology located within the individual consumer.

Douglas and Isherwood (1979) set out a view of consumer society which is based firmly on anthropological studies of primitive societies. They argue that it is entirely 'rational' for consumers to employ material artefacts in a wide range of symbolic roles in the social context. In particular, Douglas and Isherwood draw attention to the importance of material goods in providing 'marking services' - social rituals that serve to embed 
the consumer in their social group, cement social relations within the group and play an important role in maintaining information flows within the social group.

These information flows, claim Douglas and Isherwood, go far beyond the invidious 'display consumption' offered by Veblenesque critiques. They serve a vital purpose in helping the individual to maintain and improve social resilience in the face of cultural shifts and social shocks. Research from an entirely different quarter appears to reinforce these ideas. The importance of gift-giving in exchange relations has been widely explored in consumer psychology and motivation research (Belk and Coon 1993).

The notion that material goods offer a vital role in providing marking services has some resonance with the work of the Nobel prize-winning economist Amartya Sen and his collaborator Martha Nussbaum. In a seminal paper about the standard of living, Sen (1984) put forward the idea that individual well-being has to do not solely with income levels, but with the freedoms or 'capabilities' enjoyed by the individual. Some of these capabilities refer to physiological functioning - the capability to achieve adequate nutritional levels, for example. Others refer to social and psychological functioning (Nussbaum 1998 eg).

Perhaps the most important argument from the capabilities approach relates to the 'materiality' of capabilities within different societies. Sen argues that material requirements for physiological functioning tend to be fairly similar in all societies. Crucially however, the material requirements associated with social and psychological capabilities can vary widely between different societies:

'To lead a life without shame, to be able to visit and entertain one's friends, to keep track of what is going on and what others are talking about, and so on, requires a more expensive bundle of goods and services in a society that is generally richer and in which most people have, say, means of transport, affluent clothing, radios or television sets, and so on... The same absolute level of capabilities may thus have a greater relative need for incomes (and commodities) (Sen 1998, 298).

The point being made here is precisely the one that Douglas and Isherwood are making about 'marking services'. As it is presently organised, modern society has appropriated the symbolic property of commodities to play a vital role in articulating social identity, ensuring social capabilities, and maintaining social cohesion. Here is perhaps the clearest message yet that simplistic appeals to consumers to forego material consumption will be unsuccessful. Such an appeal is tantamount to demanding that we give up certain key capabilities and freedoms as social beings. Far from being irrational to resist such demands, it would be irrational not to, in such a society.

\section{Consumption and the Pursuit of Meaning}

Perhaps even more surprising are the insights that emerge from the literature connecting the symbolic role of consumer goods to our 'higher' self-actualisation needs. This strand of thought extends the complex symbolic nature of material consumption still further. Not only do material commodities possess symbolic properties. Not only do these symbolic properties play a vital role in constructing and maintaining personal and social identity. Material goods are also implicated in our individual and collective search for meaning. 
These insights are confirmed by fascinating evidence of the sacred properties of money (Belk and Wallendorf 1990) and consumer goods (Belk et al 1989). This evidence identifies a 'ritual substratum' of consumer behaviour in which consumers are continually engaged in a process of sacralising and desacralising material goods.

At first sight, this evidence is confusing, indicative of some even deeper form of pathology. It suggests a degree of alienation from our higher transcendental needs than even the humanists might have recognised. It conjures up a picture of empty lives, bereft of spirituality and meaning, made purposeful only by shopping. Once again, however, such a characterisation is too harsh. Though the symbolism invested in material commodities may, in the final analysis, be inappropriate, the motivation to invest that symbolism in them is a very human one.

McCracken (1998) makes the case persuasively. He argues that one of the most pressing problems any culture must deal with is the "gap between the "real" and the "ideal" in social life', the distance between our aspirations (for ourselves, for our society, for human nature) and the reality with which we are daily confronted. He identifies three common strategies for approaching this problem. The first is to retreat into naive optimism. The second is to move towards open cynicism. Ultimately, however, McCracken argues that neither of these strategies is particularly successful. Naive optimism leaves us blind to the need for social or individual change; cynicism leaves us 'the unmanageable prospect of a life without larger goals or hope'. The third strategy is to displace our ideals to some distant (and relatively inaccessible) place or time. This is the strategy that McCracken calls 'displaced meaning'. He describes it in the following way:

'Confronted with the recognition that reality is impervious to cultural ideals, a community may displace these ideals. It will remove them from daily life and transport them to another cultural universe, there to be kept within reach but out of danger... The strategy of displaced meaning contends with the discrepancy between the real and the ideal by the clever expedient of removing the ideal from the fray.' (op cit p106)

In finding a location for displaced meaning, however, a culture must choose carefully. Preferably what is needed is a place (in time or space or some imagined other world) in which the cherished ideal could have been or could potentially become a reality, and yet which is distant enough from the here and now that its reality cannot be checked - and hence cannot either be proved or disproved. This distance is an essential part of the strategy. Our displaced ideals must be far enough away and inaccessible enough that we never have to confront the question of whether they are true or false, tenable or untenable. The future, the past, the golden age, another culture (preferably far away in either space or time) are all examples of potential safe havens for displaced ideals.

McCracken does not discuss religion. But it is clear that religious faith can be construed quite precisely as a strategy for the displacement and selective recovery of meaning (Jackson 2002c). In the face of the fact that unconditional altruism, benevolence, compassion, forgiveness, harmony, and universal peace are neither pervasive realities nor even (if evolutionary psychology is to be believed) particularly successful survival strategies, they must either perish as ideals or be displaced to some other place, time or existence. Faith in the kingdom of heaven - whether it be on earth at some future date, in the 'next life', or in some other dimension altogether - offers a ready location for 
displaced meaning, a place where the meek may inherit, the wolf may lie down with the lamb, the contrite may be forgiven, the righteous blest.

At the same time, a culture that engages in the strategy of displaced meaning is faced with a very particular kind of problem: namely, the need to reestablish a limited form of access to the displaced ideals. Ideals which remain permanently displaced simply atrophy. Moreover, the recovery of displaced meaning is a delicate and potentially dangerous operation. It must provide the illusion of access to the displaced ideal without jeopardising the displacement that protects our ideals from the harsh light of day. Thus, the strategies for displaced meaning must tread a fine line between the comfort of proximity and the safety of displacement.

In the case of religious belief, this balancing act is achieved through myth, symbol and ritual. The act of worship, the ritual of the mass, the sacrament of the holy communion are all essential elements of the strategy for recovering displaced meaning in the Christian tradition, for example.

McCracken's argument is that consumerism operates quite precisely as a strategy for displaced meaning. Material artefacts, he says, are 'bridges' to displaced meaning. He argues that commodities are in fact particularly suited to operate in this capacity for a number of reasons. They are bigger, in some sense, either than the objects themselves or even than their use value. They are both concrete and symbolic. They are themselves; and at the same time they are signifiers of life as it should be, as we would like it to be. They are material representations of our expectations for the future, of the status to which we aspire, of the comforts that we deserve, of the rewards that we fervently hope will be showered upon us. They serve as bridges to our displaced ideals.

Crucial to the success of consumer goods in their capacity as bridges to displaced meaning is their ability not to undo the work of displacement. We purchase a particular commodity in the belief that it will bring us closer to our displaced ideals. The object itself is both concrete and symbolic and it is precisely this duality which renders material commodities so successful as bridges to displaced meaning. One may possess the object. But possessing the object is not the same as possessing the ideal. This duality allows us both to approach displaced meaning and also to preserve its displacement.

Furthermore, there is a dynamic and self-perpetuating mechanism at work in all this. The sheer variety of consumer goods allows for an almost infinitely variability in the pursuit of displaced meaning. And since material goods evoke displaced ideals without ever actually recovering them, they serve as bridges without ever foreclosing the need for future bridges, without ever diminishing the appetite for future consumption. Perversely, therefore, a significant part of the success of consumer purchases as bridges to meaning is in failing to recover the displaced ideals. This is exactly what we need from a strategy for recovering displaced meaning: to give the illusion of access to our ideals, and yet never in reality to approach them. Thus, in a sense, consumer culture perpetuates itself precisely because it succeeds so well at failure! 
In summary, it should be clear from the preceding sections that consumer behaviour is an extraordinary rich phenomenon, engaging individuals, communities and society as a whole at many different levels.

In particular, it is clear that no purely functional account of material goods is going to deliver a robust model for understanding consumer behaviour: because functionality is not the point (or at least not exclusively the point). We consume not just to nourish or protect ourselves or to sustain a living. We consume in order to identify ourselves with a social group, to position ourselves within that group, to distinguish ourselves with respect to other social groups, to communicate allegiance to certain ideals. To differentiate ourselves from certain other ideals. We consume in order to communicate. Through consumption we communicate not only with each other but with our past, with our ideals, with our fears and with our aspirations. We consume in pursuit of meaning. 


\section{Changing Consumption Patterns}

Parts 1 and 2 of this report pointed to a paradox. On the one hand, research calls into question the assumption implicit in many government policies that material consumption is the main source of our well-being. While some consumption is essential for us to meet our basic needs, there is evidence that continuing growth in consumption fails to improve our quality of life. Most of the world's cultural and spiritual traditions are quite clear about the pitfalls of the pursuit of wealth, emphasising instead the importance of human relationships, caring for the poor, and respecting the land and other life. The rhetoric in the sustainable development debate has also pointed in a similar direction. At the time of the millennium celebrations, the world's leading politicians made speeches asserting that it was time to move on from $20^{\text {th }}$ century materialism and individualism, to rebuild community and work for peace.

On the other hand, we do not seem to understand well enough what shapes our own behaviour. We appear to be locked in to current consumption patterns by a combination of market incentives, psychology and conditioning, social structures and norms, institutional frameworks, cultural values and narratives.

Yet, consumption patterns do change, continually. New fashions replace the old symbols of status and community membership. With greater awareness, we do abandon habits that harmed us. And at times of national emergency, whole populations are willing to embrace austerity - no doubt we all hope that it won't come to that. This part of the report starts by reviewing research into the way the culture of consumption evolves.

\section{Consumption differences and change processes}

Lifestyles and consumption patterns have been transformed over the last century, coevolving with technology, infrastructure, markets, the legal system, social structure and culture. The transformation appears to have gone largely in one direction: towards increased levels of consumption, and towards higher levels of resource use despite increasing resource efficiency. It also appears to have spread mostly from one geographical centre, with many new patterns of consumption being developed in the United States and diffusing to the rest of the world. On the whole, consumption patterns shift from being seen as luxuries, to being seen as normal consumption, to being seen as basic necessities - this shift occurred with car ownership in Britain between 1960 and 1980 .

Technology is often identified as a major factor in consumption change (Røpke, 2001), although technology itself is clearly shaped by the social and cultural context, including the local culture of consumption (Landes, 1969; Rosenberg, 1994). There are strong parallels between the patterns of technology diffusion and those of the diffusion of culture and institutions (Grübler, 1998; Grübler and Nakicenovic, 1991), which should not be surprising since technologies are embedded in culture and institutions.

Economic and technological progress does not inevitably determine consumption. For example, the growth in car use in Europe over the last half century was originally a product of deliberate government policy, especially in France, Germany and Britain. These governments funded and planned the development of the road and motorway 
infrastructure. They provided financial support for the car industry and in some cases owned and directed it for a period. It is only in the last decade that governments began to take seriously the idea of transport demand management. Even now, car production continues to be seen as a positive sign of economic activity.

Consumption patterns vary considerably with culture. For example, meat consumption in India is far below the levels of other countries at similar income levels (FAOSTAT, 2002). Planning policies and culture play a major role in shaping expectations regarding housing type and area per person. Wilhite (1998) has found substantial differences between Norway and Sweden in the use of lighting. There are also tremendous differences within individual countries in the culture of consumption. These differences are part of the dynamics of changing consumption over time.

Harper (2000) has found in workshops and interviews with students from all world regions that lifestyle ideals are converging on an affluent middle class standard. On the other hand, Wilk (1998) has researched the role of emulation in consumption change, evaluating in particular the extent to which populations in the south are influenced by the media to imitate consumption patterns in the north, and asking whether global consumption patterns are converging. His findings indicate that the international emulation effect is more limited than is often suggested, but that low-income households do tend to follow the consumption patterns of the local middle class.

The innovation and diffusion of consumption patterns has probably been studied most by the marketing profession, which tends to focus on identifying different segments of the market and their role in the take-up of new products and technologies. Broadly, the standard model of consumption change follows the sequence:

1. Many consumption patterns, lifestyle options or fashions are maintained or developed by minority groups (e.g. Mohican haircuts; vegan diets; electric cars)

2. Some of these behaviours are taken up by celebrities, or promoted by business, government or the media to particular target groups in the population

3. The behaviours are adopted by the target (or another) group

4. The behaviours spread to other groups.

The next section explores evidence for the growth of a set of more sustainable consumption behaviours.

\section{Moving towards sustainable consumption}

Doane (2002) finds that "ethical" purchases are increasing their market share by about $10 \%$ per year. The most significant areas are food (free range, organic, vegetarian); housing (green mortgages); household goods (eco-labels such as FSC); and cosmetics (without animal testing). There is also growth in the market share of green energy and environmentally friendlier transport options. These trends originate in the initiatives of pressure groups providing information on the social and environmental harm associated with conventional products and from co-operative and other ventures promoting ethical 
products. But mainstream retailers and their customers are increasingly important in their growing market share (Michaelis, 2003a).

\section{Cultures of consumption}

In 2000, MORI carried out a research study for the Co-operative Bank into ethical consumerism (Hines and Ames, 2000). They interviewed nearly 2000 adults, asking what were the persuading factors for them in their purchasing choices, what were their most important sources of information, and what choices they actually made with regard to ethical consumption. They investigated the correlation between answers to these questions with socio-economic grouping, choice of newspaper, and voting intentions. The respondents were clustered into five groups which Hines and Ames describe as:

1. "Do what I can" (49\%). This largest segment is close to the average on most indicators although older than the other groups. They are concerned about environmental and social issues but their ethical concerns carry less weight in their purchase decisions than service, convenience and branding.

2. "Look after my own" $(22 \%)$. These consumers are mostly young, single, on low incomes, and tabloid readers. They are the least concerned with social and environmental issues.

3. "Conscientious consumers" (18\%) are a higher-income group, evenly split between broadsheet and tabloid readers, and between Conservative and Labour voters. Their purchase choices are motivated primarily by quality but also strongly by social and environmental issues.

4. The "Brand Generation" (6\%) are the youngest group, mostly tabloid readers, and the group most concerned with their peer group, and least likely to view newspapers as a source of information. As the label suggests, they are the group most likely to pay attention to branding in their product choices, but their primary concern is product quality. They are also very concerned with, and likely to talk to their friends about, social and environmental issues.

5. "Global watchdogs" (5\%) are the hard core ethical consumers. They are the second oldest group, the highest income group, and include the highest proportion of broadsheet readers. They are least likely to cite television and the most likely to mention charities or other organisations as sources of information.

Government policies for sustainable consumption might need to engage these different groups in completely different ways. The first two groups might not shift towards more sustainable consumption patterns unless forced to do so by product standards and price incentives. The third and fourth are more open to shifting their choices. Conscientious consumers might respond to moral messages encouraging more responsible consumption. The Brand Generation might adopt more sustainable consumption if this were clearly bound up with their peer group identity. The last group are already committed to sustainable consumption and would probably benefit most from better information. 
For the time being, the segment of the market prepared to make substantial behavioural adjustments for sustainability is small, but attitudes may be shifting. Inglehart (1997) draws on value surveys in 43 countries to claim that a postmaterial culture is emerging. The shift is at least in part a cohort effect. Just as Putnam (2001) finds that the breakdown of community in the United States is resulting from younger people participating less in groups, Inglehart finds that it is the younger cohorts who place less emphasis on material possessions and more on being part of a social network.

\section{Linking narrative and consumption culture}

How much do values and attitudes expressed in surveys tell us about sustainable behaviour? A gap between attitudes and action has been reported by numerous researchers (e.g. Kempton, 1997; Vlek et al., 2000). Vlek et al, propose a model of consumption change that suggests that action depends on a convergence of "needs", "opportunities" and "abilities". Moisander (1998), studying consumers in Denmark, found that attitudes to environmental issues were uncorrelated with environmentally friendly choices, except for those who identified themselves as "green consumers", and those who felt they had a moral duty to consume responsibly. This growing group of responsible consumers were not so much people with particular attitudes about the environment; they were people with particular narratives about themselves, their identities, and their obligations.

Thompson and Rayner (1998) cluster attitudes to sustainable development in terms of Cultural Theory, an approach to categorising types of culture that links up closely with personal narratives. The theory has been developed and applied mainly by Mary Douglas (Douglas and Ney, 1998) and Michael Thompson (Thompson et al, 1990). It defines cultures along two axes: strong or weak group relationships; and symmetric or asymmetrical relationships. The resulting types are illustrated below. Dake and Thompson (1999) found from a household survey in Britain that lifestyles and consumption patterns were correlated with these cultural types. There may be some correlation between these five types and those identified by Hines and Ames.

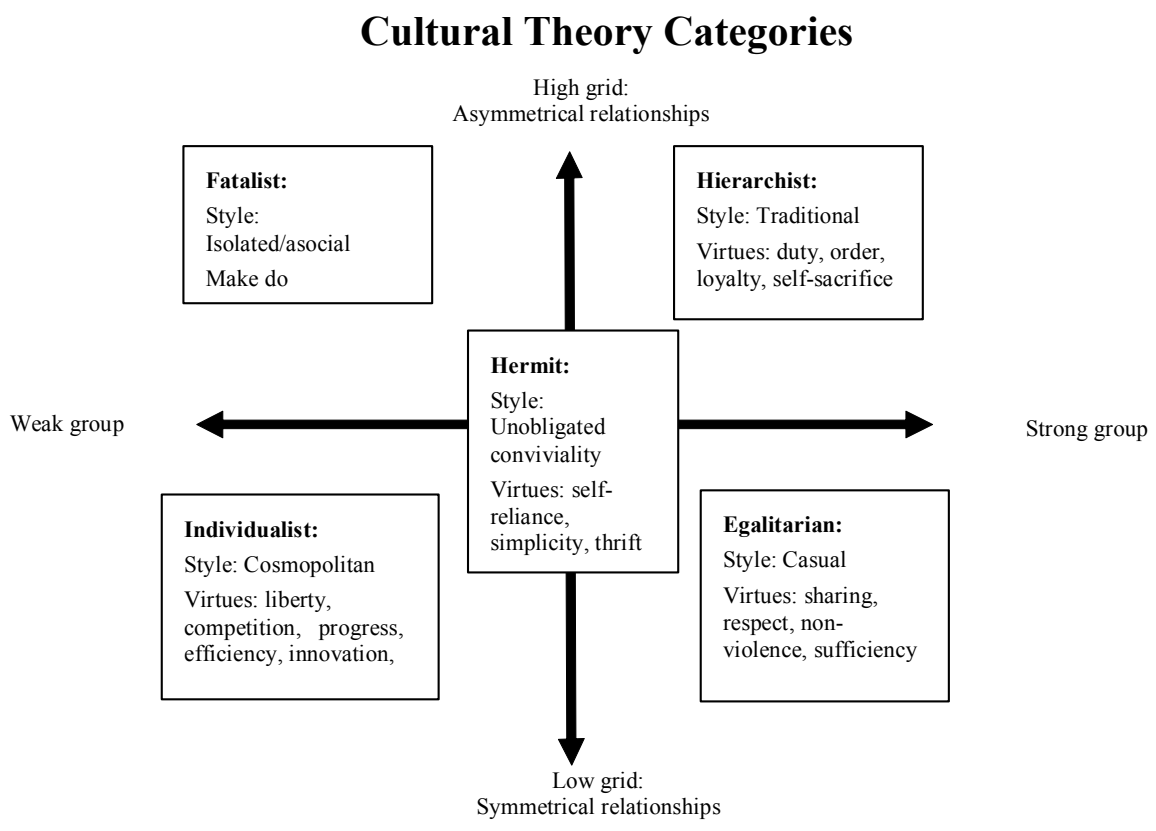


Thompson and Rayner suggest that three of the cultural types play a strong role in the sustainable development debate: individualists, hierarchists and egalitarians. These are the types with active views about the way society ought to be run. The other two types in the figure tend to be passive or unconcerned with regard to social organisation.

The table below shows how the three active voices might position themselves in the sustainable consumption debate, and how these positions are rooted in basic assumptions about moral goals and the role of consumption in individual and collective well-being.

Table: Three Voices in the Consumption Debate

\begin{tabular}{|c|c|c|c|}
\hline & Traditional/hierarchy & Individualist/market & Egalitarian/community \\
\hline Example & $\begin{array}{l}20^{\text {th }} \text { century civil service } \\
\text { or large company }\end{array}$ & $\begin{array}{l}\text { stock exchange, Silicon } \\
\text { Valley }\end{array}$ & $\begin{array}{l}\text { monastery, professional } \\
\text { association }\end{array}$ \\
\hline Goals/moral goods & stability, order, solidarity & $\begin{array}{l}\text { liberty, opportunity, } \\
\text { efficiency }\end{array}$ & $\begin{array}{l}\text { equality, fairness, } \\
\text { solidarity }\end{array}$ \\
\hline $\begin{array}{l}\text { Social role of } \\
\text { consumption }\end{array}$ & $\begin{array}{l}\text { communicate/affirm } \\
\text { status/role }\end{array}$ & $\begin{array}{l}\text { self-expression, affirm } \\
\text { individual identity }\end{array}$ & $\begin{array}{l}\text { membership of group, } \\
\text { affirm collective identity }\end{array}$ \\
\hline $\begin{array}{l}\text { Problems with } \\
\text { consumption }\end{array}$ & $\begin{array}{l}\text { tastelessness of mass } \\
\text { consumption; loss of } \\
\text { traditional foods, crafts, } \\
\text { social structure. }\end{array}$ & $\begin{array}{l}\text { market distortions and } \\
\text { barriers constrain freedom } \\
\text { of choice: insufficient } \\
\text { consumer } \\
\text { information/empowerment }\end{array}$ & $\begin{array}{l}\text { inequity between } \\
\text { consumers; exploitation of } \\
\text { workers; unfair terms of } \\
\text { trade. }\end{array}$ \\
\hline $\begin{array}{l}\text { Diagnosis of } \\
\text { environmental } \\
\text { problems } \\
\text { (Thompson and } \\
\text { Rayner, 1998) }\end{array}$ & $\begin{array}{l}\text { population growth, } \\
\text { irresponsible behaviour by } \\
\text { firms, individuals }\end{array}$ & $\begin{array}{l}\text { lack of market signals } \\
\text { reflecting environmental } \\
\text { goods/costs }\end{array}$ & $\begin{array}{l}\text { profligate consumption, } \\
\text { pursuit of power/self- } \\
\text { interest by firms, } \\
\text { individuals }\end{array}$ \\
\hline $\begin{array}{l}\text { Preferred solutions } \\
\text { for sustainability }\end{array}$ & $\begin{array}{l}\text { regulation, pollution } \\
\text { control, better planning }\end{array}$ & $\begin{array}{l}\text { internalisation of } \\
\text { environmental costs, better } \\
\text { frameworks for } \\
\text { technological/business } \\
\text { innovation }\end{array}$ & $\begin{array}{l}\text { public/stakeholder } \\
\text { dialogue leading to shared } \\
\text { goals/solutions }\end{array}$ \\
\hline $\begin{array}{l}\text { Preferred mode for } \\
\text { sustainable } \\
\text { consumption }\end{array}$ & consuming responsibly & consuming efficiently & consuming less \\
\hline
\end{tabular}

Recognising the diversity of positions in the debate, and their rootedness in fundamental values, is an important step in being able to carry the debate forward. The next step is understanding how different positions evolve and how pathways can be found that accommodate apparently conflicting viewpoints.

\section{Reflexivity and organisational change}

Part 3 of this report reviewed the literature on evolutionary psychology, which draws on an understanding of natural selection to find explanations for behaviour patterns. A related literature seeks to use the principles of evolution and selection to explain cultural change. Dawkins (1986) suggested that thought and culture could evolve through the 
replication and selection of "memes" - mental objects, thoughts, snatches of music, images etc. This concept has been developed, in particular, by Dennett (1993) into a theory of consciousness. Within this theory, our self-consciousness is a result, in essence, of having a story or narrative about ourselves - a personal history. The nature of this self-description evolves with culture. Indeed, within this theory, culture is essentially made up of the memes that are current in the group or population. Consumption patterns result from a particular subset of memes.

The theory of memes has given rise to the approach known as "viral marketing", in which companies seek to promote their products by spreading information through selfreplication in target groups, e.g. via e-mail, rather than by broadcasting messages through the mass media. It has also given rise to some new perspectives on the process of social and cultural change. In particular, it offers credence to the idea that, just as individuals become self-conscious by developing narratives about themselves, their histories and their aims, so communities and institutions can become self-conscious or reflexive, with collective identities and goals.

Modern society is becoming more complex with the development, at one extreme of scale, of global connectivity (Mulgan, 1997) and, at the other extreme, of our subjective experience of an interior self (Taylor, 1989). At both ends of the scale, complexification is closely linked to technological development, in particular in communication. In the past, writing and later printing transformed culture (Eisenstein, 1983). Now, the radical increase in access to information and the reduction in time and cost associated with communication are almost certainly having major social impacts but it is too early to predict the outcome (Castells, 1997).

Social, psychological, economic and technological complexification may be one of the reasons why society is over-reaching its ecological resource base (Tainter, 1996). Growing economic and industrial complexity makes it harder for individuals to recognise the connections between their actions and the environment. But complexification may also be the means through which society learns to respond. An essential element of the complexification process is the increasing reflexivity, or selfquestioning, of institutions. This trend is described by Giddens (1994) as posttraditionalism and by Beck (1988) as reflexive modernisation.

\section{Changing consumption in reflexive communities}

As described above, a reflexive community is essentially one that has a story about itself. Discourse and narrative are particularly important in the current context because they provide a bridge between individual psychology and the culture of society at large. Campbell (1959) expounds a theory of mythology that links culture and ethics to narratives about a) the nature of the world; b) human nature; c) the nature of society and d) the nature of "the beyond" - the divine or spiritual. Taylor (1989) similarly links our narratives to our understanding of our selves, our conception of society, and our notions of what is "good".

Living in a post-traditional society exposes us to tensions between fundamental principles, setting freedom against equality, individual against community, our rights against others' needs, and humanity against nature (Michaelis, 2000a) These tensions are often reflected in our consumption and lifestyle choices. Life has become more 
complicated, partly because we have no simple, shared narrative about our goals and ethics as a society.

MacIntyre (1985) laments the state of ethics in modern society, in particular the interminable debates over ethical principles. He argues that ethics cannot work as universal principles, but only if they emerge as practical rules for living within a specific functioning cultural tradition. Such a tradition includes a set of cultural practices, a narrative framework, and an ideal of the good life. Gare (1995) believes that the creation of practical traditions for sustainable living depends on re-establishing local communities and reducing the power of nation states. This may seem a lost cause in the face of the globalisation of markets, media and human relationships, and it might be more helpful to look for the development of such traditions at a variety of different scales, in a large number of overlapping and intersecting communities.

What does it take to rebuild communities and how far do we want to go down that line? Bauman (2001) describes the tension between individual and community - between freedom and security - as interminable. Society currently puts too much emphasis on individual freedom, or at least an illusion of freedom, and communities have deteriorated as a result. But we would not want to go too far in the opposite direction, giving up liberty for the security of the community.

There have been many efforts to develop community discourses on sustainable consumption. One movement that has been popular in the United States is Simplicity Circles, discussion groups that explore practical and spiritual dimensions of living more simply and provide mutual support to members over a long period. Some simplicity circles have been set up in Britain. But perhaps the most successful movement in Europe is that of the international NGO, Global Action Plan. GAP sets out explicitly to encourage a change in lifestyles through awareness raising and dialogue (Burgess, 2003). Originating in the United States, GAP now has programmes in several countries including Britain.

When GAP began to work in Britain, it initially focused on providing households with information packs, enabling them to work out their own environmental impacts and identify priorities for changing their habits. Surveys and interviews (Hobson, 2001) show that participants valued the information but did not feel strongly motivated to change their behaviour. On the whole, reflecting on their choices helped them to become clearer about their reasons for maintaining their current lifestyles, rejecting the rational arguments for change offered in the packs. They were more concerned about issues of social justice linked to their consumption than about the environmental impacts.

\section{EcoTeams}

More recently, GAP UK has begun to adopt the EcoTeam approach, which has been the main strategy in other countries, especially the Netherlands. GAP starts from the assumption that many people have attitudes consistent with moving towards environmentally sustainable behaviour, but that they do not have sufficient information to do so, nor do they believe that they alone can make a difference. Hence a collective, community-based approach is crucial. 
The EcoTeam is a group of 6 to 10 people who might be neighbours, members of the same religious organisation, or members of some interest group or club. They meet once a month and discuss ideas, experiences and achievements related to the EcoTeam programme. The programme is based on a workbook which addresses six areas in turn: waste, gas, electricity, water, transport and consumption. The Workbook explains each theme, the goals of GAP, and a number of actions that can be taken by households to reach those goals. The programme takes a total of eight months. Each team is supported by a coach or by a reporting centre.

EcoTeam members work towards becoming "global citizens" by changing aspects of household behaviour. The emphasis is on the household rather than the individual, so that EcoTeam members work with other household members to change behaviour in areas such as waste separation and recycling, water use, energy use, and transport.

GAP has set up EcoTeams in several countries and has developed Workbooks and support material for different countries. While GAP monitors the results of its programme, the most detailed evaluation of quantitative results has been carried out in the Netherlands (Staats and Harland, 1995), where EcoTeams have typically achieved reductions in car use and consumption of energy and water of around $10 \%$, and reductions in waste of around 40\%. Similar results are achieved in British groups (personal communication, GAP UK, 2003). Maiteny (2002) found that participants in GAP's programmes were most likely to maintain behaviour changes if they were motivated by a strong and positive link to personal meaning and identity. For some, the deciding factor was a spiritual experience changing their sense of their relationship with nature. Behaviour changes that respond to negative incentives (e.g. price or regulation) or anxiety are not maintained when the incentives are removed.

\section{Living Witness Project}

One of the authors of this report is co-ordinator of the Living Witness Project, involving a "learning network" of 17 Quaker meetings around Britain (Michaelis, 2002). The project focuses on building a sense of community around sustainable living, and on collective experimentation and learning, both within the individual meetings and in the network that links them. In our network we have found that it is important to move towards congruence between our values and ideals, our lifestyles, and practical action in the wider community.

We find that individuals participating in the groups start from quite different motivations but all of them are in essence concerned with at least one of three fundamental questions:

1. How can we improve our own quality of life, and our own personal and spiritual flourishing?

2. How can we enable our communities and society at large to flourish?

3. How can we contribute to the flourishing of the natural world?

Sustainable living needs to address all three of these concerns - indeed, they are the keys to each other. 
Based on our experience and that of GAP, there does seems to be more potential for a shift in consumption patterns if people are engaged in a community dialogue than if they simply reflect on their own lives. There are many reasons for this:

- We think differently when we discuss issues as part of a group than when we work through arguments on our own. In groups, we develop our personal stories in forms that we would be happy to tell to others.

- Groups can sometimes be more creative than individuals; and one person may have the solution to another person's problem.

- Peer group solidarity is a key factor in enabling us to shift our behaviour.

- We are able to do things as groups that individuals could never do alone.

Meanwhile, if dialogue can be a basis for change, it can also be the basis for rejecting change. Our experiences so far have shown the need for a light touch, discouraging prescriptive talk - people are alienated by "shoulds" and "oughts". We have also found the value of mixing educational sessions with fun, including eating together; and the need for information provision in a variety of forms to suit different interests and abilities. We can confirm the observation of NEF (1998) that community building is a slow process. Support is often required over an extended period, 18 months to two years, before a group becomes self-sustaining. But we have also found that a little community support can help motivate participants to take the initiative to a surprising degree. Three of the groups involved in the project have won substantial grants for their work and several are involved in the wider community.

\section{Institutions at the heart of the reflexive society}

It is hard for community groups to make very significant changes in their lifestyles without support from the social, cultural and economic context of the wider society. Reflection about the flourishing of humans, society and nature also needs to happen in society's main culture-forming institutions. These include the media, schools, religious organisations and businesses.

\section{The media}

Critics of consumerism highlight the mass media, especially popular television, as symptoms and causes of cultural decline into mass consumption (e.g. Baudrillard, 1970). They also point to the presence of the western media in developing countries as a cause of rapid cultural change, with the adoption of western consumer values and the loss of traditional culture. However, such critics usually base their criticism on their own reading of media content, rather than on systematic observation of the way audiences respond to the media.

Understanding of the influence of the media on their audiences has evolved over the last fifty years (Dickinson et al., 1998; Reisch, 2000). In the 1940s and 1950s, the media were often viewed as instruments of direct social control influencing audiences directly in a stimulus-response manner. However, studies aiming to demonstrate such an influence have been inconclusive. The effects of the media on audience behaviour cannot be separated from the social and cultural context and history of the audience. 
Media influences can be observed directly in changes in the way people talk in interviews and focus groups. But direct effects on consumption are much harder to measure and few attempts have been made to do so. While advertising campaigns occasionally have immediate results, promoting particular products or brands, changes in lifestyles and ingrained habits are likely to take much longer. And consumption is likely to be shaped by many factors in the social and cultural context. It is a daunting task to try to establish the relative importance of the media, schools, workplaces and other sources of ideas and attitudes.

While media content may or may not shape audience behaviour in a simple, direct way, it certainly has an influence. From the 1960s, media analysts have developed a much more sophisticated picture of the range of ways in which the media are involved in social, cultural and political life. Researchers have moved away from viewing audiences as passive objects of media influence. The "uses and gratifications" school of media studies in particular has concentrated on understanding how individuals use the media as active agents. It finds that viewers use television, for example, as a means of escape, a source of a vicarious community, a topic of conversation, a means of reinforcing personal identity, and a means of "surveillance" of the outside world (McQuail et al., 1972).

Other researchers have aimed to understand the media's influence as part of, and in interaction with, viewers' social and cultural context. The media have been found to influence the way their audiences "frame" issues - supplying some of the fundamental assumptions, concepts and worldviews that shape the way they think (McCombs, 1994). The print media have been shown to play a central role (along with politicians and powerful institutions) in setting the agenda for public concerns and debate. Narratives about consumption that are rehearsed on television, whether in advertisements, political sound-bites, soap operas or consumer magazine shows, are used by viewers to justify their own behaviour (Dickinson, 1998) - i.e., as a source of ethics.

It remains open to debate how much the media reflect consumer culture and how much they help to shape it. Nevertheless, the media are clearly gatekeepers in the cycling of narratives and symbols in society, and hence in the evolution of the culture of consumption (Michaelis, 2001).

\section{$\underline{\text { Schools }}$}

The incorporation of "citizenship" into the national curriculum, with references to consumerism and the rights of consumers, offers new opportunities to explore issues linking community and consumption. In addition to their role in educating children, schools are often at the centre of community activity. Schools have often been the focus of efforts to develop more sustainable communities.

There are numerous initiatives where school children are involved in vegetable growing. DEFRA and DES have established a project called Growing Schools, which encourages the use of gardening and growing as part of the curriculum. School meals also offer an opportunity for educating children about healthy nutrition, the relationship between food and the environment (see box). 
Several schools have also developed transport plans. Direct effects on local traffic may be slight. For example, following adoption of a transport plan by Horndean Community School, the share of children cycling to school doubled, but travel by car declined by only 3\% (HCC, 1999). Nevertheless, such programmes raise awareness and can provide a focus for project work supporting the curriculum.

\section{$\underline{\text { Religious groups }}$}

Faith organisations are often identified as fertile ground for developing new community initiatives. One of GAP UK's main EcoTeam programmes involves church groups. Putnam (2001) identifies churches as the last sanctuary of community activity in the United States. Participants in faith organisations often have strongly-held values that enable them to stand aside to some extent from the individualism and materialism of the consumer society. The EcoCongregations Programme, started as part of Going for Green and still sponsored by Churches Together in Britain and Ireland, is continuing to generate activity in religious groups to green their places of worship and reflect on members' personal lifestyles. Other initiatives include the Noah Project, a Jewish environmental campaign that provides advice on environmental action in the home; and Operation Noah, a campaign by Christian Ecology Link to promote action on climate change, places a central emphasis on changing lifestyles.

\section{$\underline{\text { Businesses }}$}

The role of the business community is a key issue in the debate about sustainable consumption. Businesses were central to the creation of the technology and wealth that transformed society in the last century. They provide most of the products and services that people consume. And they invent, design, develop and market those products and services, so that they shape the environmental impacts of consumption. The business community, along with the mass media and governments, has helped to promote and affirm a culture that emphasises the core values of consumerism: material prosperity, individual success, technological progress, consumer choice. And through employment and remuneration practices, the business community helps to shape household budgets, aspirations, the availability of leisure time, and the degree of insecurity.

\section{Coombes Nursery and Infant School}

Coombes Nursery and Infant School, in Arborfield near Reading, seeks to exemplify a sustainable way of life in the school community and grounds. The following is an extract from the 2002 OFSTED report:, which found the school to be "excellent" in all respects:

...the headteacher has organised the
imaginative development of the school
grounds as a resource for teaching and
learning. Because of her exceptional
leadership, the whole community works
increasingly to improve and enrich the
environment for the pupils. Developments in
the grounds include such features as
meditative walks, ponds, large geological rock
samples, including a scaled-down Stonehenge
known as 'Coombeshenge', a maze and areas
for growing pumpkins and sunflowers. There
are fruit trees from which the fruit is harvested
every year by the pupils, and sheep graze in a
pen. Pupils' learning and their spiritual, moral
and social development are enhanced by what
they can see and experience around them.

OFSTED, 2002.

The achievements of this school are due to the values, imagination, enthusiasm and stamina of the headteacher and staff, working with parents, governors and the local community. They suffer the same constraints as most state schools, including ill-maintained 1960s-designed buildings and the drive to deliver academic standards at minimal cost. They have shown that performance targets can be met to an exemplary level through an approach to the learning experience that starts from the child interacting with the natural environment. 
While the business community is currently focusing its engagement with the sustainable development agenda on its contribution to eco-efficiency, Welford (2000) argues that much more is required. Businesses must develop cultures that are congruent with the values both of their staff, and of their communities within which they operate. Welford advocates more stakeholder involvement in corporate decision making, engaging in continuous dialogue with their employees, customers, investors, and the communities in which they operate, seeking to establish a shared understanding of values, goals and priorities. Some firms have recognised this need as a result of direct public challenges to their ways of doing business (e.g. the Shell experience with Brent Spar). Others have adopted a deliberate strategy to make themselves leaders in "corporate social responsibility".

Many companies have found that caring for the environment helps to motivate their employees, makes the company more effective and enriches shareholders. But they may not think deeply enough about how they might have to change to meet their social obligations fully. Many use stakeholder processes as defensive public relations exercises. While it became fashionable in the 1980s for firms to develop "mission statements" with commitments to social goals, few are structured or managed in ways that encourage employees to treat those goals as their own or provide them with opportunities to help shape the corporate vision.

Michaelis (2003b) suggests that, if businesses are to engage fully in a dialogue with their critics, companies may need to be prepared to ask themselves some very difficult questions: what is their core purpose in trading? what is their relationship to others in society? how far do their environmental responsibilities extend back up the supply chain, and to the in-use and post-consumer impacts of products? what are their social ideals? and what constitutes moral corporate behaviour? Perhaps the most important question to ask is whether, on a thorough examination, their wider social duties are in conflict with their obligations to shareholders, and how far any such conflict can be reconciled.

Local multistakeholder processes and community groups

Partnership among different stakeholders is a central theme in the sustainable development discourse, being emphasised in the Rio Principles and Agenda 21. But experience so far has been patchy, with most of the examples of successful partnership occurring at a local level (Hemmati, 2002).

Groups may be initiated by local governments as part of their Local Agenda 21 programmes, they may be set up by campaigning organisations, they may develop as

\section{Community Composting}

Devon has more Community Composting projects than any other county in the UK. This is largely due to the unique partnership between the District and County Councils. Money raised from recycling banks in the County goes towards community recycling and composting projects and other recycling initiatives. The first composting group was set up in 1992. There are now 20 groups operating with more set to follow. Recycling credits are paid for finished compost based on the reduction in waste going to landfill. Payments help to provide the core funds for each project. A newsletter is published giving information to those interested in setting up new schemes.

Source: www.othas.org.uk/dccn/ 
special interest groups within existing organisations such as religious bodies or workplaces, or they may emerge through groups of neighbours getting together.

Some of the best experiences in efforts to develop more environmentally sustainable lifestyles have come for groups that have focused on building a sense of community. Several programmes in Britain work with disadvantaged communities, including the EnCams Sustainable Communities Programme, Groundwork, the Community Development Foundation, and the Shell Better Britain Campaign. For these programmes, improving the quality of life of participants is central.

LA21 initiatives have gained experience with a wide variety of approaches for community building and strategy development (NEF, 1998; Walker, 1997), but on the whole, they have stuck to the "low hanging fruit". They have taken on measures that clearly benefit the local economy and the quality of life for local communities, while possibly bringing some resource savings (monitoring and evaluation is usually weak). Few have tried to come to grips with the challenge of sustainable consumption.

Local groups are able to achieve a great deal with little funding. However, there has been a strong tendency recently for groups to focus on waste issues, because of the availability of funds from the landfill tax scheme. Often, projects focusing on waste are used as opportunities to address broader aspects of consumption, but it is harder for local groups to find support for projects addressing issues such as sustainable transport and housing.

Another considerable source of energy for the Local Agenda 21 movement in Britain has been the Women's Institute (WI, 2003). Several local groups are working with local councils to map and monitor wildlife. Consumption-related initiatives include producing a local recycling guide, a "sustainable" cookbook, and refurbishment of a local railway station.

If multistakeholder processes are to begin to address the more fundamental questions behind sustainable development, and especially sustainable consumption, there will be a need for leadership and support. This is the focus of the next section.

\section{Leadership in a post-traditional society}

Increasing social mobility and questioning of cultural assumptions and norms are resulting in the obsolescence of traditional models of leadership and authority (Senge, 1990; Griffin, 2002). The emerging theory of organisational change responds to this challenge mostly within corporate structures, but many of its insights may be applicable to the leadership role of government in a post-traditional society. It may be particularly value in addressing the question of strategies for sustainable consumption, given that this is an area where governments appear both unable and unwilling to take a strong lead.

\section{Organisational learning}

Organisational change theory places particular emphasis on the role of leadership in facilitating a process of reflection and learning. To survive in a complex, rapidly changing world, an organisation needs to be flexible and to have effective mechanisms to learn (Lane and Maxfield, 1995). The Oxford Commission on Sustainable 
Consumption identified adaptability as a central feature of a sustainable society (OCSC, 2000).

Organisational learning takes many different forms. Bateson (1972) distinguishes between "proto-" and "deutero-" learning. Proto-learning involves adjustments to practices within the existing set of rules and routines. Deutero-learning involves developing new rules. Argyris and Schon (1978) popularised the concepts of "single" and "double loop" learning for management. Double loop learning is demanding of both managers and others in an organisation. It involves being willing to question fundamental assumptions about the world around us, about human nature, and about the purpose and operating framework of the organisation. It may involve learning:

- in the first person, challenging assumptions about ourselves and our own psychology

- in the second person, challenging assumptions in interactions in the group, and

- in the third person, challenging assumptions about the wider world (Torbert, 2001; Reason and Torbert, 2001).

Effective learning may require reflection on visions, strategies, practical actions, and approaches to evaluation (Torbert et al, 2001).

Within the sustainable consumption debate "consuming efficiently" can be understood as single loop learning, while "consuming less" would entail double loop learning. The idea of "consuming efficiently" avoids questioning the basic assumptions of the consumer society. The goal of "consuming less" challenges (inter alia) the link between material consumption and the Good Life.

One of the most common blocks to organisational change is the gap, often unconscious, between the "espoused theory" of management and the "theory in practice" (Argyris and Schon, 1996). In the sustainable consumption agenda, the "espoused theory" is that governments are seeking to promote equity and quality of life while protecting the environment. Their "theory in practice" is revealed by their emphasis on indicators such as economic growth, by the lifestyles of government ministers, and by the procurement decisions and other policies of government departments, from health and education to defence and international development.

\section{Leadership for organisational change}

Successful organisational learning is linked by many researchers to the personal development and learning of leaders and other organisation members. Torbert et al (2001) have developed a model of levels of psychological development, and find that successful organisational change depends on management teams including individuals who are relatively advanced in their personal development.

Beck and Cowan (1996) develop a similar model of the development of psycho-social modes of functioning, which Wilber (2001) has linked to Maslow's (1954) hierarchy of motivations (see Part 3 of this report). These are summarised in the table below (the language is adapted to avoid the heavy use of jargon by Beck and Cowan). The table 
also identifies the environmental policies and communication strategies that might be effective in seeking to influence people and organisations operating in the different modes.

Table 3. Psycho-social modes

(from Michaelis, 2003c, based on Beck and Cowan, 1996)

\begin{tabular}{|c|c|c|}
\hline Mode & Human nature, needs, self image & $\begin{array}{l}\text { Effective sustainability policies and } \\
\text { communication strategies }\end{array}$ \\
\hline Survival & $\begin{array}{l}\text { Impulsive; reactive; instinctive; } \\
\text { physiological and survival needs }\end{array}$ & Planning, standards. \\
\hline Kin-attachment & Centred on kin; belongingness needs & $\begin{array}{l}\text { Qualitative guidance on lifestyle and } \\
\text { consumption }\end{array}$ \\
\hline Heroic power & $\begin{array}{l}\text { Heroic power. Assertion of force. } \\
\text { Esteem needs. }\end{array}$ & Regulation and policing \\
\hline Hierarchy & $\begin{array}{l}\text { Emphasis on role in hierarchy. Esteem } \\
\text { and belongingness needs. }\end{array}$ & $\begin{array}{l}\text { Codes of practice. Incite duty, moral } \\
\text { obligation. Seek to develop new social } \\
\text { norms. }\end{array}$ \\
\hline Strategic & $\begin{array}{l}\text { Strategic, rational individual } \\
\text { calculating and pursuing personal } \\
\text { advantage. Esteem and actualisation } \\
\text { needs. }\end{array}$ & $\begin{array}{l}\text { Objective information, pricing, clear } \\
\text { responsibilities backed up by law. }\end{array}$ \\
\hline Pluralistic & $\begin{array}{l}\text { Emotional, communitarian, focus on } \\
\text { personal growth, equality. } \\
\text { Actualisation and belongingness } \\
\text { needs. }\end{array}$ & $\begin{array}{l}\text { Education. Stakeholder processes. Ensure } \\
\text { opportunities for green consumption. }\end{array}$ \\
\hline Synthetic & $\begin{array}{l}\text { Compassionate: able to take multiple } \\
\text { perspectives. Motivated by learning, } \\
\text { integration of complex systems. }\end{array}$ & $\begin{array}{l}\text { Comprehensive policy packages justified } \\
\text { by multiple rationalities to address } \\
\text { different subcultures and situations. }\end{array}$ \\
\hline Holistic & $\begin{array}{l}\text { Integrated. Creative synthesis of } \\
\text { perspectives. }\end{array}$ & $\begin{array}{l}\text { Collaborative development and } \\
\text { implementation of policies and strategies. }\end{array}$ \\
\hline
\end{tabular}

All of these authors emphasise that any individual or organisation may operate in several modes at once, and may move continually between modes. Just as research has failed to support Maslow's hypothesis of a hierarchy in human needs, research into cultural and psychological types (with which some of the modes correspond) also challenges the notion of a hierarchy in psycho-social modes (Douglas and Ney, 1998; Thompson et al, 1990; Jung, 1923; Myers and Myers, 1993). However it does find that in successful development, individuals learn to value and express the thought patterns and capabilities of other types.

A key feature of successful managers is that they are not attached to a particular worldview or psychological or cultural frame (the "synthetic" and "holistic" modes in the table). They can cope with diversity, having a facility for seeing the world from others' points of view. They recognise the value of different perspectives, and are able to manage the interaction between them. They are also willing to reflect on their own behaviour and to learn from others (Torbert et al, 2001).

The role of the leadership is to facilitate dialogue, reflection and learning in four realms:

1. Developing shared vision

2. Designing a strategy 
3. Allocating responsibility for specific action

4. Establishing clear mechanisms for monitoring and evaluation.

Within this framework, change management is then largely a matter of increasing the reflexivity in the organisation - seeking to engage all of those involved in a learning process in pursuit of the organisation's ultimate goals.

Part 5 of this report will develop some of the implications of this approach for government. 


\section{Policy Opportunities}

This final section of the report explores the policy opportunities that flow from a broader and deeper understanding of the sustainable consumption debate. Clearly conventional policy intervention will have a significant role to play in promoting sustainable consumption. Ensuring that prices reflect environmental and social costs, and that consumers have access to adequate information about consumption choices will always be important policy instruments.

In addition, however, this section highlights some of the less obvious roles for government policy, for example in influencing the social, cultural, institutional and ethical conditions within which individual consumer choices are negotiated. Particular attention is paid to the ways in which government can do more to support and encourage initiatives from schools, NGOs, community groups, and religious organisations. We also highlight the role of government in social innovation: encouraging and promoting engagement, dialogue, experimentation, learning and the diffusion of successful initiatives for change.

\section{Conventional policy frameworks}

Typically, the conventional role of government in policy-making in relation to sustainable consumption (as in other contexts) is defined in one of two ways.

The first is one in which government seeks to understand and influence consumer behaviour from the outside. The government is understood as the manager of the system. Consumers are understood as entities with behaviour that is to some degree explicable and responsive to stimuli in predictable ways. Measures in this set include: regulations and standards, market instruments and planning.

The second role is one in which government seeks to influence consumers through information, education and other psychological measures. There is a great deal of experience with such measures, especially in areas such as health, safety, nutrition and addiction. Governments have long used the education system, media messages, media regulation, and labelling to try and persuade people to consume differently. Measures in this set include the use of taxes and criminal law to send a deterrent signal or strong moral message. In these cases, government is behaving as an expert advisor, moral guide, or surrogate parent.

In a subsequent section we shall go on to address measures that treat consumers as partners with government and other institutions in a collective dialogue about societal goals and strategies for achieving them. These measures are much less well understood than conventional policy frameworks, but there is a growing interest in them (OECD, 2001; Banuri et al., 2001; Sathaye et al., 2001).

\section{Instrumental policies: "government in control"}

First generation environment policies: pollution prevention and control

Environmental regulations have long been applied to consumer products and technologies, and to consumer behaviour. Substantial environmental improvements have been achieved through the smokeless zones established in many British cities since 
the 1950s, and through vehicle emission standards that have gradually tightened since the 1960s. Considerable progress has also been achieved through minimum standards for the energy efficiency of domestic appliances and for home insulation.

But the stringency of policies is limited by government unwillingness to challenge industry. There has been a trend in recent years towards developing voluntary agreements with industry, as in the case of fuel economy targets for cars manufactured in Europe.

Economists tend to view regulations and standards as second-best "command and control" policies, constraining innovation and choice. However, they may sometimes be the most feasible and cost-effective way of achieving goals, such as energy efficiency improvements in domestic appliances and vehicles (e.g. DOE, 1995; Michaelis, 1996).

Second generation policies: market instruments

From the 1980s, similar sets of policy recommendations began to emerge from institutions such as the OECD, the IPCC and the World Bank. During the 1990s, they began to be endorsed by environmental NGOS and even business organisations. These organisations start from the analytical framework of equilibrium economics or liberal market theory. According to these frameworks, policies are justified where they correct for market failures, externalities, or barriers to the effective operation of the market (e.g. Pearce et al, 1989; Sathaye et al., 2001). The main emphasis is on three kinds of measure:

1. remove subsidies and other forms of market protection that support environmentally damaging behaviour (Larsen and Shah, 1992; OECD, 1996, 1997a; Roodman, 1996; Greenpeace, 1997)

2. shift taxes from "goods" such as employment and investment to "bads" such as pollution and resource use, basing tax levels on environmental and social costs (OECD, 1997b);

3. create new markets in environmental "goods" and "bads" (e.g. cap and trade greenhouse gas emission permits; allocate tradeable fishing quotas, etc.; OECD, 1999)

While "getting the prices right" has been a mantra of environment policy for much of the last 15 years, few environmental taxes have been implemented and the evidence base for their impacts on consumer behaviour is remarkably weak (OECD, 2000). Nevertheless, examples of environmental economic instruments in Britain include the climate change levy, the GHG trading scheme, the (stalled) road fuel duty escalator, and the landfill tax.

Estimates in the literature (e.g. Kägeson, 1994; EC, 1995) of the tax increases justified by environmental and social costs are small compared with current energy prices in Britain. Internalisation of environmental costs might have a significant impact on choices between technologies (e.g. by changing the relative cost of coal vs. gas fired power generation), but effects on consumer demand in areas such as residential 
electricity and urban transport are small - typically of the order of 10\% (IPCC, 1996; OECD, 1997a). Achieving significant and ongoing reductions in energy use for road transport or aviation would require policies such as the abandoned fuel duty escalator, with prices rising over the long term by 3-5\% per year (ECMT, 1995; Michaelis, 1997).

Feasibility is a central issue for environmental taxes and charges. New taxes and charges are usually opposed on the grounds of their claimed distributional impacts, or effects on vulnerable groups. British government experience with VAT on domestic fuel and road fuel duty indicates the moral complexity and political difficulty in increasing taxes linked to resource consumption. However, recent research suggests that the challenge of gaining public approval is largely a matter of appropriate policy design and effective public communication. A survey of European attitudes towards environmental tax reform revealed not so much outright hostility towards environmental taxation as problems of trust in government and clarity in the design of measures (Dresner et al 2002).

Local governments often find it easier than national government to introduce charges, partly because there may be more transparency in the use of the revenues, and partly because of a greater sense of finding local solutions to local problems. The experimentation in London with congestion charging is a promising start. Parking fees are a good example of an effective, feasible and widely applied pricing mechanism.

\section{Planning law, incentives and guidance}

Of the established areas of policy development, urban and transport planning is perhaps the one that is most prepared to make deliberate (and often misconceived) attempts to shape lifestyles and behaviour. Planning decisions have a direct effect on the kinds of home people are able to live in, including their size, the way they are used, and their energy consumption for heating. Urban form, in particular the density and distribution of homes, workplaces, and services, has been identified as a key determinant of personal travel and energy use (Newman and Kenworthy, 1990; Armstrong, 1993). Local governments routinely use the planning process to influence the generation of traffic. Perhaps one of the most controversial aspects of planning practice has been its use to encourage community development through the provision of communal spaces and leisure facilities (Barton, 2000). The decision to allow or restrict development of major supermarkets has a considerable impact on shopping habits and food choices, as well as on local communities and economies (Simms et al, 2002). 


\section{Information and persuasion: government as expert and moral guide}

The most extensive experience of efforts to influence consumption is probably that related to tobacco, where measures include education in schools, direct public information through the media, regulation of advertising and other media representation of smoking, health warnings on packaging, controls on purchase (age constraints), and high levels of duty. Policies on tobacco amount to a concerted effort to act on all of consumers' psychological levers to change behaviour; their limited impact illustrate how difficult this can be. While smoking has become less accepted as a normal activity in Britain, and most smokers say they want to give up, levels of smoking have stopped declining in recent years (DH, 1998).

Governments have sought to influence environmentally-significant consumption using much milder measures than those applied to tobacco, most recently in the Going for Green programme launched in 1996, and in the Are You Doing Your Bit? campaign, which ran from 1998 to 2000 . These programmes sought to provide guidance to the public on ways of reducing the environmental impacts of consumption. Are You Doing Your Bit? focused on simple ways of saving energy and water, and reducing waste and pollution. It included a road-show and public information broadcasting on TV. Suggestions for action in a leaflet from Are You Doing Your Bit? include:

- Turn down the thermostat by $1^{\circ} \mathrm{C}$

- Don't put more water in the kettle than you need

- Turn off the TV when you aren't watching it

- Use your council recycling scheme if they have one

- Buy products with less packaging

Going for Green demanded a little more intelligence from the public, providing a fairly complex guide (EcoCalc) for lifestyle evaluation based on the principle of ecological footprints. This programme generated a number of activities now maintained by the government-sponsored charity EnCams, including the EcoSchools and EcoCongregations programmes. EnCams' main focus is litter prevention but it also runs a programme promoting community initiative (the Sustainable Communities Programme).

A MORI review in 1999 found that public awareness of these government campaigns was low compared with that of the campaigns of environmental NGOs such as Greenpeace and Friends of the Earth. A review for DETR in 2001 reveals some discomfort in the government relationship with Encams. DETR was seeking to focus its energy on the Are You Doing Your Bit? campaign, of which it remained the primary operator (DETR, 2001a).

Nevertheless, DETR's evaluation of the effects of Are You Doing Your Bit? were positive, showing a high level of public awareness of publicity, and increased awareness of the link between personal behaviour and the environment. They emphasise the importance of providing simple messages about little things that everyone can do. They 
also emphasise the value of combining media messages with direct contact, as in the case of their road-show (DETR, 2001b). However, they do not offer evidence for changes in consumer behaviour. Indeed, experience with energy conservation and environmental programmes over several decades and in various countries finds that public awareness-raising alone is ineffective in changing behaviour (Stern, 1986). In particular, information may be discounted if it comes from organisations that are not trusted - for example, because they do not follow their own advice.

\section{Towards a strategy for sustainable consumption}

Price incentives, awareness raising, and voluntary agreements with industry are unlikely to be enough to achieve the scale or pace of consumption change needed to move towards a sustainable society. Sustained global reductions in resource use would require levels of price incentives that are currently politically unimaginable. In any case, the economic theory that advocates such measures as the most efficient way of achieving sustainability ignores the many other ways in which governments can engage in the processes that shape consumption.

In this final section, we set out a broad framework for developing a more comprehensive strategy for sustainable consumption. In the scope of this report, we cannot possibly develop detailed policy proposals. Rather, we confine ourselves here to identifying some general principles (based on the research reviewed in Parts 3 and 4 of this document) and then outlining some broad indicative policy avenues.

\section{Principles for a Sustainable Consumption Strategy}

Part 3 of this report reviewed the research into the factors shaping consumption and the links between consumption and quality of life. One of the principal lessons from this extensive literature is the sheer complexity that underlies consumer motivations. Consumers are engaged individually and collectively in satisfying material needs, in display, in sexual competition, in social interaction, in ritual, in the provision of marking services, and in the transcendental pursuit of meaning.

Moreover, it is difficult, in any particular instance, to tear these different modes and levels of engagement apart. Functionality, status, social interaction, ritual, and symbolic meaning are woven together in tightly-layered veil of material complexity. Clearly this complexity presents policy-makers with considerable challenges. Nonetheless, it is possible to identify several specific policy implications from this body of research.

a) Current government policy presumes that increasing levels of economic consumption are a pre-requisite for improving the quality of life. Research does not support this presumption. The relationship between material commodities and social well-being is much more complex than conventional policy suggests. A shift in government policy would be justified to place more emphasis on other contributors to quality of life, such as health, community engagement and meaningful work.

b) Current thinking suggests that it would be infeasible for government to change individual consumer behaviours. Research does not support this presumption. Government plays a vital role in shaping the cultural context within which 
individual choice is negotiated through its influence on technology, infrastructure, market design, institutional structures, the media, and the moral framing of social goods.

c) Current government policy presumes that market frameworks allow consumers, on the whole, the freedom to choose the lifestyle that best reflects their needs and desires. Research does not support this presumption. Individual choices are constrained by a variety of social, institutional, and cultural factors. Consumers often find themselves 'locked in' to unsustainable consumption. Government intervention is vital to facilitate change.

Part 4 of the report concentrates on the mechanisms through which consumption patterns can change. Our principal conclusions from this review are:

a) Society is becoming "post-traditional" with increasing questioning of values and culture. A variety of movements and networks have developed in Britain, in which small groups learn about environmental and social issues, explore lifestyle options and take collective action. These groups offer a model for change. Their scope to demonstrate sustainable lifestyles would be greatly increased by government policies to establish a more supportive context.

b) In this post-traditional society the government role is shifting from control to a "change management" approach, encouraging learning. Successful leadership in the learning process requires government to be willing to listen to others, and to question its own assumptions and practices. It involves ensuring the congruence of its visions, strategies, practical actions, and evaluation processes.

c) An effective government strategy for sustainable consumption will need to be developed on a collaborative basis with stakeholders. It will incorporate a wide range of measures. Policy packages might include: regulation and standards, qualitative guidance on sustainable lifestyles, codes of practice, market incentives, education, stakeholder processes, and the development of effective monitoring and indicators.

\section{Components of a Sustainable Consumption Strategy}

The broad principles suggested above could be served by many different forms of strategy. In this final section we suggest some possible components for such a strategy, emphasising 1) aligning strategic vision, rhetoric and practice; 2) shaping the cultural context of consumption; 3) supporting non-governmental initiatives and innovation; 4) establishing programmes and networks to nurture successful initiatives and encourage their replication; and 5) monitoring and learning from outcomes.

\section{Aligning government vision and rhetoric with policies and practices}

A first step in a strategy for sustainable consumption would be to align policy with vision and rhetoric in all government departments. This means, first, initiating a public or multistakeholder dialogue on a vision for sustainable consumption. It could use an approach such as that developed in Integrated Assessment Focus Groups (e.g. Kasemir et al, 2000) but it could use all channels available to initiate a debate - through the media, in schools and universities, in workplaces and in religious organisations. Such a 
dialogue might build on existing futures exercises in Britain such as that of the Foresight Programme (Foresight, 1999), and on more detailed sector scenarios (Green and Vergragt, 2002; Banister and Stead, 1999). It would need to involve an in-depth process to ensure full understanding, engagement and buy-in from participants.

Many initiatives for sustainability from enthusiastic individuals and groups fail partly because of conflicts between the policies and programmes of different government departments. A major challenge for government is to bring policies and measures in diverse departments - for example, on road and house building, agriculture, employment, education and energy fully into line with sustainable consumption goals.

Sustainable procurement policies are another important part of a coherent strategy for sustainable consumption. Government procurement sends strong signals to the rest of society about its priorities. It can also be an important lever for encouraging the introduction of sustainable products and for bringing down costs. Some of the most important procurement areas may include construction, energy, transport services and food. It may be necessary for central government to develop guidelines for providers of contracted out services and services in the hands of local authorities, including schools and hospitals.

Regular reviews or audits are needed to identify where and how government policies and practices fail to support the strategy. These might need to be carried out by an independent agency or consultants. If the strategy is to be fully effective, government will need to be prepared to learn from the findings and act on them. Developing congruent policies throughout government is crucial but it is likely to be a slow process requiring sensitivity and strong leadership.

\section{Shaping the culture of consumption}

Individual consumer choices are negotiated in a complex institutional, social, and cultural context. The role of government in designing and shaping that context is crucial.

There has been a tendency in conventional policy to assume that the government should play as little role as possible in regulating or intervening in consumer choice. The doctrine of consumer sovereignty has dominated both economics and politics for several decades. One of the key lessons from Part 3 of this report is that this doctrine 
underestimates the complexity of consumer motivations and the wider context of individual choice. Consumers are not always willing participants in unsustainable consumption patterns. More often they are locked into unsustainable consumption by factors outside their individual control.

By contrast, governments are not innocent bystanders in the negotiation of consumer choice. They already influence the culture of consumption in a variety of different ways. In some cases, this influence proceeds through the imposition of regulatory and fiscal structures. In other cases it proceeds through the absence of such regulations and incentives. Most often it is a complex combination of the ways in which government does intervene, and the ways in which it chooses not to intervene.

For example, the way in which the energy market was liberalised offers consumers a remarkable choice of energy suppliers who compete vigorously for custom on the basis of the lowest unit price. The same liberalisation process has actively impeded robust and fair mechanisms for choosing green electricity or for improving domestic energy efficiency. Or to take another example, government regulation of complementary health is reducing some of the alternatives available to consumers, while its failure to regulate 'viral marketing' leaves consumers open to a variety of ethically dubious strategies for advertising more conventional pharmaceuticals. In similar fashion, government has seen fit, probably rightly, to ban cigarette advertising, and yet it leaves unregulated the advertising of products that threaten the success of its own $\mathrm{CO}_{2}$ emission targets.

Selective policy intervention has an enormous influence on the institutional and social context of consumption. The long-standing failure of successive UK governments to reduce inequalities in the distribution of incomes has the effect of increasing competitive social pressures, and reducing affiliative, cooperative and social behaviours. Successive de-regulation of retail and trade has eroded the cultural space previous afforded by religious and social practices.

At the highest level, government intervention has moulded and shaped the cultural context within which individual choice is negotiated. Much of this intervention has been in the direction of promoting unsustainable consumption. There is now an urgent need to re-examine the role of government in this respect. Sustainable consumption policy must devise constructive ways of promoting social, cultural and ethical conditions that support and nurture sustainable consumer behaviour.

\section{Supporting initiatives for change}

Part 4 of this report highlighted a small number of non-governmental initiatives for changing consumption patterns. The British Government already supports several of these initiatives, including the work of NGOs such as GAP and Groundwork, through the Environmental Action Fund (DEFRA, 2003). Most of the grants on issues related to consumption come under the heading of "understanding and awareness of sustainable development". DEFRA also works through Encams, as mentioned above. On the whole, the model of partnership appears to be one where the Government is control, whether through funding, advice or providing direction.

Other mechanisms could be used to fund initiatives for sustainable consumption - for example, by making Carbon Trust funds available for community energy saving and 
renewable energy projects; or by enabling communities to take part in greenhouse gas emission trading.

The Government could explore ways of getting more in touch with the experience of organisations and individuals that are working for change, to understand how it can best support them. While central government might be supportive in principle of many initiatives to develop sustainable forms of transport, housing or food production and consumption, innovations are often prevented at the local level, whether by local government, business or residents. For individuals and groups seeking to set up new initiatives, the institutional hurdles can appear insuperable. Funding is crucial, but it is just one way of supporting local initiatives. Another might be to establish an agency specifically to provide legal and other advice. It might, for example, help community groups to undertake feasibility studies, or to apply for planning permission or funding for their projects.

There have been many analyses of the barriers to achieving environmental goals such as climate change mitigation (Sathaye et al, 2001). But the idea of government policies being obstructed by social "barriers" implies a low valuation of the priorities of those affected (Shove, 1999). In finding the way through conflicts of interest, there is no good substitute for spending time listening to those involved. Again, this may be a task best carried out by experienced staff in agencies with some independence from government.

\section{Encouraging replication}

An effective strategy would need strong mechanisms to publicise successful initiatives for sustainable consumption, and to encourage their replication. One model is that of the Energy Efficiency and Environmental Technology Best Practice Programmes. These could be extended or used as a model for new programmes addressing other areas, such as education for sustainability, sustainable urban and transport planning, sustainable housing and sustainable communities.

Replication of initiatives can be encouraged by giving awards and accreditation (e.g. to companies that have demonstrated successful non-car based commuting schemes, or to local groups developing innovative ideas for community engagement). It can also be supported by conferences, web sites, newsletters, local offices (e.g. following the pattern of energy efficiency offices), and regular discussion groups.

\section{$\underline{\text { Strategy review and learning }}$}

The review process is an essential part of any strategy. Major issues in developing an effective review and learning process for the sustainable consumption strategy might include:

- Choosing indicators - are new indicators required, beyond the government's existing set, which cover equity and environment well, but do not adequately address quality of life. Are composite indicators such as the ecological footprint useful in strategy review? 
- Ensuring openness and transparency. The government may not be the best organisation to review its own strategy. An independent auditing organisation may need to be involved.

- Developing a culture that is open to making mistakes and learning from them.

\section{Concluding Remarks}

Clearly, the suggestions set out in the preceding section are neither exhaustive nor detailed. The development of a strategic policy approach to sustainable consumption is beyond the scope of this document. Indeed, one of the arguments implicit in what we have said is that the first task of government should be to undertake a comprehensive strategic review on sustainable consumption. Such a task is beyond the scope of any individual researcher or set of researchers. It is nonetheless a task of considerable urgency, if government is to bring any influence to bear on the long-term project of achieving sustainable development.

In this final section of the paper, we have done little more than draw out key policy lessons on sustainable consumption, and point to some indicative avenues of intervention.

These suggestions depart from conventional policy prescription in two specific ways. In the first place, they emphasise the vital role that government has to play in shaping the institutional, social, cultural and ethical context within which individual consumer behaviour is negotiated. Secondly, they offer a model for government policy which goes beyond the rigidity of 'control' and 'persuasion' and is based instead on the idea of government and public as collaborators and learning partners in the process of change.

It is our hope that these insights will provide the starting point for an extensive, collaborative dialogue on sustainable consumption in the UK. 


\section{References}

Allen, W 1982. Midnight Economist: broadcast essays III. Los Angeles, International Institute for Economic Research.

Anderton, A 2000. Economics ( $3^{\text {rd }}$ edition), Causeway Press, Ormskirk, UK.

Argyris, C. and E. Schon 1996. Organizational Learning II: Theory, Method and Practice, Addison Wesley, Reading, MA.

Armstrong, D.M. 1993. Transport infrastructure, urban form and mode usage: an econometric analysis based on aggregate comparative data. in Regional Science Association Thirty Third European Congress, Moscow, 24-27 August 1993. Northern Ireland Economic Research Centre, 48 University Road, Belfast, N. Ireland, BT7 1NJ.

Banister, D. and D. Stead 1999. 'Policy scenario building - methods and results', TENASSESS Final Workshop, Vienna, May 1999.

Banuri, T., J. Weyant, G. Akumu, A. Najam, L. Pinguelli Rosa, S. Rayner, W. Sachs, R. Sharma and G. Yohe 2001. 'Setting the stage: climate change and sustainable development'. Chapter 1 in B. Metz, O. Davidson, R. Swart and J. Pan (eds.), Climate Change 2001: Mitigation. Contribution of Working Group III to the Third Assessment of the Intergovernmental Panel on Climate Change. Cambridge University Press. pp.73-114.

Barthes, R 1973. Mythologies. Paladin, London.

Barton, H 2000. Sustainable communities. London: Earthscan.

Bateson, G 1972. Steps to an Ecology of Mind, University of Chicago Press, Chicago.

Baudrillard, J 1968. The System of Objects, extracted in Selected Writings, 1988, Polity Press, Cambridge, 24-5.

Baudrillard, J 1970. The Consumer Society- myths and structures (reprinted 1998), Sage Publications, London.

Bauman, Z 2001. Community: Seeking Safety in an Insecure World, Cambridge, England, Polity Press.

Baumann, Z 1998. Work, Consumerism and the New Poor, Open University Press, Milton Keynes.

Beck D and C Cowan 1996. Spiral Dynamics: Mastering Values, Leadership and Change, Blackwell, Oxford, England.

Beck, U 1988. Risk Society: Towards a New Modernity, English translation by M. Ritter, 1992, London, Sage.

Begg, D, S Fischer and R Dornbusch 2003. Economics ( $7^{\text {th }}$ edition), McGraw-Hill, Maidenhead, UK.

Belk R 1988. Possessions and the Extended Self, Journal of Consumer Research, 15, 139-168.

Belk, $\mathrm{R}$ and $\mathrm{G}$ Coon 1993. Gift-giving as agapic love: an alternative to the exchange paradigm based on dating experiences, Journal of Consumer Research 20, 393417.

Belk, R and M Wallendorf 1990. The Sacred Meaning of Money, Journal of Economic Psychology 11, 35-67.

Belk, R, G Ger and S Askegaard 2003. The Fires of Desire: a multi-sited inquiry into consumer passion, Journal of Consumer Research,

Belk, R, M Wallendorf and J Sherry. 1989. The Sacred and the Profane in Consumer Behaviour - Theodicy on the Odyssey. Journal of Consumer Research 16, 1-38.

Bocock, R 1993. Consumption. Routledge, London. 
Bourdieu, P 1984. Distinction - a social critique of the judgement of taste, Routledge and Kegan Paul, London.

Burgess, J 2003. 'Sustainable consumption: is it really achievable', Consumer Policy Review, Volume 11, No. 3., pp. 78-84.

Campbell, C 1998. Consumption and the Rhetorics of Need and Want, Journal of Design History 11(3), 235-246.

Campbell, J 1959. The Masks of God: Primitive Mythology Volume 1 of 4. Arkana, Penguin Group, New York, NY.

Castells, M 1997. The Power of Identity: The Information Age: Economy, Society and Culture, Volume II, Blackwell, Oxford.

Cohen, M and J Murphy 2001. Exploring Sustainable Consumption - environmental policy and the social sciences, Pergamon Press, Oxford.

Cronin, H 1991. The Ant and the Peacock - sexual selection from Darwin to today, Cambridge University Press, Cambridge.

Dake, K and M Thompson 1999. 'Making ends meet, in the household and on the planet', GeoScience 47, 417-424.

Daly, H 1996. Beyond Growth - the economics of sustainable development, Beacon Press, Boston.

Darwin, C 1859. On the Origin of Species by Means of Natural Selection, reprinted (1985) by Penguin Classics, London.

Dawkins, R 1976. The Selfish Gene, Oxford University Press, Oxford.

Dawkins, R 2001. Sustainability doesn't come naturally: an evolutionary perspective on values, The Environment Foundation's 'Values Platform for Sustainability' Inaugural Lecture, Wednesday $14^{\text {th }}$ November 2001, The Royal Institution, London.

Dawkins, R 1986. The Blind Watchmaker. Longman, London. Reprinted by Penguin, London, 1991.

de Geus, M 1999. Ecological Utopias: Envisioning the Sustainable Society, International Books, Utrecht.

DEFRA [Department of Environment, Food and Rural Affairs] 2003 Environmental Action Fund Newsletter, Issue 11.

Dennet, D 1993. Consciousness Explained, Penguin, London.

DETR[Department of Environment, Transport and the Regions] 2001a. In House Policy Consultancy: Financial Management and Policy Review of Going for Green and Tidy Britain Group (EnCams), DETR, London.

DETR 2001b. 'Are You Doing Your Bit?', presentation at Expert Workshop on Information and Consumer Decision-Making, OECD, Paris.

DH [Department of Health] 1998. Smoking Kills: A White Paper on Tobacco, The Stationery Office, London.

Dichter, E 1964. The Handbook of Consumer Motivations: the psychology of consumption. McGraw Hill, New York.

Dickinson, R 1998. 'Modernity, consumption and anxiety: television audiences and food choice' in Dickinson, R., R. Harindranath and O. Linné (eds.) Approaches to Audiences: A Reader, London, Arnold, pp. 257-271.

Dickinson, R, R Harindranath and O Linné 1998. 'Editors' introduction: approaching audience studies' in Dickinson, R., R. Harindranath and O. Linné (eds.) Approaches to Audiences: A Reader, Arnold, London, pp. xi-xvi. 
Dittmar, H E 1992. The Social Psychology of Material Possessions - to have is to be. St Martin's Press, New York.

Doane., D 2002. Ethical Purchasing Index, 2002, The Co-operative Bank, Manchester.

DOE [US Department of Energy] 1995. Effects of Feebates on Vehicle Fuel Economy, Carbon Dioxide Emissions, and Consumer Surplus. Energy Efficiency in the U.S. Economy, Technical Report Two DOE/PO-0031. United States Department of Energy, Washington, DC.

Donovan, N, D Halpern and R Sargeant 2002. Life Satisfaction: the state of knowledge and implications for government, The Prime Minister's Strategy Unit, Cabinet Office, London.

Dosi, G, K Pavitt and L Soete 1990. The Economics of Technical change and International Trade. Harvester Wheatsheaf, London.

Douglas, M 1976. Relative Poverty, Relative Communication, in Halsey, A (ed) Traditions of Social Policy, Basil Blackwell, Oxford.

Douglas, M and B Isherwood 1979. The World of Goods - towards an anthropology of consumption, Penguin Books, London.

Douglas, M, D Gasper, S Ney and M Thompson 1998. Human Needs and Wants, Chapter 3 in Rayner and Malone 1998.

Douglas, M and S Ney 1998. Missing Persons: The Concept of the Person in the Social Sciences, ....

Douthwaite, R 1992. The Growth Illusion - How Economic Growth Has Enriched the Few, Impoverished the Many and Endangered the Planet. Green Books, Bideford, Devon.

Doyal, L and I Gough 1991. A Theory of Human Needs. Macmillan, London.

Dresner, S, N Gilbert and T Jackson 2002. Environmental Tax Reform - what does Europe think? Summary Report on a Framework V Project EVGI-CT-19990004 for the European Commission, University of Surrey, Guildford.

Durning, A 1992. How much is enough? W.W. Norton, New York.

EC [European Commission] 1995. ExternE: Externalities of Energy. Report EUR 16522 EN. EC DG XII, Science, Research and Development, Brussels and Luxembourg.

ECMT/OECD [European Conference of Ministers of Transport and Organisation for Economic Co-Operation and Development] 1995. Urban Travel and Sustainable Development. OECD, Paris.

Edwards, T 2000. Contradictions of Consumption: concepts, practices and politics in consumer society, Open University Press, Milton Keynes.

Eisenstein, E L 1983. The Printing Revolution in Early Modern Europe, Cambridge University Press, Cambridge, England.

Elgin, D 1993. Voluntary Simplicity. William Morrow, New York.

Falk, P and C Campbell (eds) 1997. The Shopping Experience. Sage Publications, London.

FAOSTAT 2002. Statistical database of the UN Food and Agriculture Organisation. http://apps.fao.org/ Accessed on 27 June, 2002.

Farley, J and R Costanza 2002. 'Envisioning shared goals for humanity: a detailed, shared vision of a sustainable and desirable USA in 2100', Ecological Economics, 43 (2002) 245 - 259.

Fine, B and E Leopold 1993. The World of Consumption, Routledge and Kegan Paul, London. 
Foresight 1999. Environmental Futures, Foresight, Department of Trade and Industry, London.

Freund, P and G Martin 1994. The Ecology of the Automobile. Black Rose Books, New York.

Fromm, E 1976. To Have or to Be? Jonathon Cape, London.

Galbraith, J K 1958. The Affluent Society. Penguin Books, Harmondsworth,

Gare, AE 1995. Postmodernism and the Environmental Crisis, London, Routledge.

Giddens, A 1994. "Reflexive institutions" in U. Beck, A. Giddens and S. Lash, Reflexive Modernisation.

Green, K and G Vergragt 2002. 'Towards sustainable households: a methodology for developing sustainable technological and social innovations', Futures, 34(2002)381-400.

Greenpeace 1997. Energy Subsidies in Europe: How Governments Use Taxpayers' Money to Promote Climate Change and Nuclear Risk, Greenpeace International Climate Campaign, Amsterdam.

Gronco, J and A Warde 2001. Ordinary Consumption. Routledge, London.

Grübler, A and N Nakicenovic 1991. Evolution of Transport Systems: Past and Future. RR-91-8. International Institute for Applied Systems Analysis, Laxenburg, Austria.

Grübler, A 1998. Technology and Global Change. Cambridge University Press, Cambridge, UK.

Haggett, C 2000. Control, Risk and Identity: the social ideology of the car, MSc Dissertation, University of Surrey.

Haire, M 1950. Projective Techniques in Marketing Research, Journal of Marketing 14, 649-56.

Harper, P 2000. The Lifestyle Lab, Schumacher Lecture, Centre for Alternative Technology, Machynlleth, Wales.

HCC [Hampshire County Council] 1999. Horndean Community School Transport Plan: 1998 Review, Hampshire County Council, Winchester.

Heap, B and J Kent 2000. Towards Sustainable Consumption - a European perspective, The Royal Society, London.

Hemmati, M 2002. Multi-Stakeholder Processes for Governance and Sustainability, Earthscan, London.

Herber, L 1963. Our Synthetic Environment. Jonathon Cape, London.

Hines $\mathrm{C}$ and A Ames 2000. Ethical Consumerism: research study conducted by MORI for the Co-operative Bank. Presentation available at http://www.cooperativebank.co.uk/downloads/ethics/ethics_mori.pdf

Hirsch, F 1977. Social Limits to Growth. Revised edition 1995. Routledge, London.

Hirschman E 1980. Comprehending Symbolic Consumption - three theoretical issues. in Hirschman and Holbrook (eds) 1980.

Hirschman, E and M Holbrook (eds) 1980. Symbolic Consumer Behaviour, proceedings of the conference on consumer aesthetics and symbolic consumption, Association for Consumer Research, New York.

Hobson, K 2002. 'Competing discourses of sustainable consumption: does the "rationalisation of lifestyles" make sense', Environmental Politics, Vol. 11, No. 2, pp. 95-120. 
IEA [International Energy Agency] 1997. Energy Statistics of OECD Countries and Energy Statistics and Balances of Non-OECD Countries, IEA Diskette Service, OECD, Paris.

IIED 1998. Consumption in a Sustainable World: Report of the Workshop Held in Kabelvåg, Norway, June 2-4 1998, Ministry of the Environment, Oslo and International Institute of Environment and Development, London.

Illich, I 1977. Towards a History of Needs. Pantheon Books, New York.

Inglehart, R 1997. Modernization and Postmodernization: Cultural, Economic and Political Change in 43 Societies, Princeton University Press, Princeton, NJ.

IPCC [Intergovernmental Panel on Climate Change] 1996. Technologies, Policies and Measures for Mitigating Climate Change, R. T. Watson, M. C. Zinyowera and R. H. Moss (eds.), IPCC, Geneva.

Jackson, T 2002. Consumer Culture as a Failure in Theodicy, in T. Cooper (ed), Consumption, Christianity and Creation, Proceedings of an Academic Seminar, 5 th July, Sheffield Hallam University, Sheffield.

Jackson, T 2002a. Quality of Life, Sustainability and Economic Growth, in Fitzpatrick, $\mathrm{T}$ and M Cahill (eds), Environment and Welfare, Palgrave Macmillan, London.

Jackson, T 2002b. Evolutionary Psychology and Ecological Economics - consilience, consumption and contentment, Ecological Economics, .

Jackson, T 2003. Models of Mammon - a cross-disciplinary survey in pursuit of the sustainable consumer, paper presented to the UK Environmental Psychology conference, Aberdeen, 23-25 ${ }^{\text {th }}$ June.

Jackson, T and N Marks 1999. Consumption, Sustainable Welfare and Human Needs with reference to UK expenditure patterns 1954-1994, Ecological Economics 28(3), 421-442.

Jackson, T, W Jager and S Stagl 2003. Beyond Insatiability - needs theory and sustainable consumption, paper presented to the 6th Nordic Conference on Environmental Social Sciences (NESS), June 12-14, 2003, in Turku / Åbo, Finland.

Jacobs, M 1991. The Green Economy. Pluto Press, London.

Jacobs, M 1997. The quality of life: social goods and the politics of consumption. In Greening the Millennium? The New Politics of the Environment, M Jacobs (ed), Blackwell Publishers, Oxford.

Jacobs, M and I Røpke 1999. Special Issue on Consumption. Ecological Economics 28(3).

James, W 1890. The Principles of Psychology, Henry Holt, New York.

Jung, CG 1923. Psychological Types, Harcourt, Brace, New York.

Kågeson, P 1994. Effects of internalisation on transport demand and modal split. In: Internalising the Social Costs of Transport. [European Conference of Ministers of Transport]. OECD, Paris.

Kassarjian, H and T Robertson (eds) 1968. Perspectives in Consumer Behaviour, Scott, Foresman and Company, Abingdon, UK.

Kasser, T 2002. The High Price of Materialism. MIT Press, Cambridge, Mass.

Kempton, W, JS Boster and JA Harley 1995. Environmental Values in American Culture, MIT Press, Cambridge, MA.

Lancaster, K 1966. A New Approach to Consumer Theory, Journal of Political Economy 174, 132-57. 
Landes, DS 1969. The Unbound Prometheus: Technological Change and Industrial Development in Western Europe from 1750 to the Present. Cambridge University Press, Cambridge, England.

Lane, D and R Maxfield 1995. Foresight, Complexity and Strategy. Santa Fe Institute, New Mexico.

Larsen, B and A Shah 1992. World Fossil Fuel Subsidies and Global Carbon Emissions, Policy Research Working Paper Series No. 1002, World Bank, Washington.

Lederer, K 1980. Human Needs - a contribution to the current debate. Oelgeschlager, Gunn and Hain, Cambridge, Mass.

Levett, R, I Christie, R Therivel and M Jacobs 2002. A Better Choice of Choice, Sustainable Development Commission, London.

Lewis, D and D Bridger 2001. The Soul of the New Consumer: Authenticity - what we buy and why we buy it, Nicholas Brealey, London.

Lutz, M and K Lux 1988. Humanistic Economics - the new challenge, Bootstrap Press, New York.

Macaulay, A, D Russell and D MacKie 1993. All Change! A Transport Strategy for Central Region: The Role of Workshops in Public Participation. in Seminar F; PTRC Transport, Highways and Planning Summer Annual Meeting, University of Manchester, England, 13-17 September, 1993. PTRC, London.

MacIntyre, A 1985. After Virtue, Second edition, London, Duckworth.

McQuail, D, JG Blumler and JR Brown 1972. 'The television audience: a revised perspective', Chapter 7 in D. McQuail (ed.) Sociology of Mass Communication, Penguin, Harmondsworth.

Maiteny, P 2002. 'Mind the gap: summary of research exploring 'inner' influences on pro-sustainability learning and behaviour', Environmental Education Research, Vol. 8, No. 3, pp. 299-306.

Mallmann, C 1980. Society, Needs and Rights, Chapter 2 in Lederer, K (ed) 1980.

Manoochehri, J 2002. Post-Rio Sustainable Consumption: establishing coherence and a common platform, Development 45(3), 51-57.

Marx, K 1859 [1975]. Early Writings, Penguin Books, Harmondsworth.

Mas-Colell, A , M Whinston and J Green 1995. Microeconomic Theory. Oxford University Press, Oxford.

Maslow, A 1954. Motivation and Personality, Harper \& Row, New York.

Maslow, A 1968. Towards a Psychology of Being. van Nostrand Reinold, New York.

Max Neef, M 1991. Human-scale Development - conception, application and further reflection, Apex Press, London.

McCombs, M 1994. 'News influence on our picture of the world', in J. Bryant and D. Zillmann (eds.), Media Effects: Advances in Theory and Research, Hillsdale, NJ., Lawrence Erlbaum, pp. 1-16.

McCracken, G 1990. Culture and Consumption, Indiana University Press, Bloomington and Indianapolis.

McDougall, W 1908. An Introduction to Social Psychology, $18^{\text {th }}$ edition (1923), Methuen, London.

Michaelis, L 1996. $\mathrm{CO}_{2}$ Emissions from Road Vehicles. Working Paper 1 in the series Policies and Measures for Common Action Under the UN FCCC. OECD, Paris. 
Michaelis, L 1997. Special Issues in Carbon/Energy Taxation: Carbon Charges on Aviation Fuels. Working Paper 12 in the series Policies and Measures for Common Action Under the UN FCCC. OECD, Paris.

Michaelis, L 2000a. Ethics of Consumption. Oxford Centre for the Environment, Ethics and Society, Mansfield College, Oxford, 2000, ISBN 1-900316-07-2.

Michaelis, L 2000b. Drivers of Consumption Patterns, in Heap and Kent (eds) 2000, 7583.

Michaelis, L 2001. The Media: A Resource for Sustainable Consumption, Oxford Centre for the Environment, Ethics and Society, Mansfield College, Oxford, 2001. ISBN 1-900316-14-5.

Michaelis, L 2002. 'Friends' Witness to Sustainable Living', in Consumption, Christianity and Creation, seminar proceedings, Sheffield Hallam University. ISBN 0-86339-984-3.

Michaelis, L 2003a. Distribution of Ethical Products via Major Retail Chains in the EU: UK Case Studies. Environmental Change Institute, Oxford.

Michaelis, L 2003b. 'The role of business in sustainable consumption', in press, Journal of Cleaner Production.

Michaelis, L 2003c. 'Beyond the ecological metaphor: community, reflexivity and sustainability'. Sustainable Futures Programme Research Paper, Environmental Change Institute, Oxford.

Miller, D 1995. Acknowledging Consumption- a review of new studies. Routledge, London.

Miller, G 2000. The Mating Mind - how sexual choice shaped the evolution of human nature, William Heinemann, London.

Moisander, J 1998. Motivation for Ecologically Oriented Consumer Behaviour, working paper prepared for Second European Science Foundation Workshop on Consumption, Everyday Life and Sustainability, Lancaster University, England. See http://www.lancs.ac.uk/users/scistud/esf/title.htm

Morris, C 1946. Signs, Language and Behaviour, George Braziller, New York.

Mulgan, G 1997. Connexity: How to Live in a Connected World, Harvard Business School Press, Boston, MA.

MVA 1995. Effects and Elasticities of Higher Fuel Prices. Final Report to UK Departement of Transport. The MVA Consultancy, Woking, Surrey, UK.

Myers, D and E Diener 1996. The Pursuit of Happiness, Scientific American, no 274, 54-56.

Myers, IB and PB Myers 1993. Gifts Differing, Oxford Psychologists Press, Oxford, England.

NEF [New Economics Foundation] 1998. Participation Works! 21 Techniques of Community Participation for the $21^{\text {st }}$ Century, NEF, London.

Newman, P and M Kenworthy 1990. Cities and Automobile Dependence. Gower, London.

Norgaard, R 1994. Development Betrayed - the end of progress and a coevolutionary revisioning of the future, Routledge, London.

Nussbaum, M 1998. The Good as Discipline, the Good as Freedom, Chapter 17 in Crocker and Linden (eds) 1998, 312-341.

OCSC [Oxford Commission on Sustainable Consumption] 2000. Report on the Second Session of the Oxford Commission on Sustainable Consumption, OCSC 2.8. 
Oxford Centre for the Environment, Ethics and Society, Mansfield College, Oxford.

OECD [Organisation for Economic Co-operation and Development] 1998. Ecoefficiency, OECD, Paris.

OECD 1996. Subsidies and Environment: Exploring the Linkages, OECD, Paris.

OECD 1997a. Reforming Energy and Transport Subsidies, OECD, Paris

OECD 1997b. Environmental Taxes and Green Tax Reform, OECD, Paris.

OECD 1999. Implementing Domestic Tradable Permits for Environmental Protection, OECD, Paris.

OECD 2000. Behavioural Responses to Environmentally-Related Taxes, COM/ENV/EPOC/DAFFE/CFA(99)111/FINAL, OECD, Paris.

OECD 2001. Information and Consumer Decision Making for Sustainable Consumption, Report of an OECD Workshop, ENV/EPOC/WPNEP(2001)16/FINAL, OECD, Paris.

OECD 2002. Towards Sustainable Household Consumption? Trends and Policies in OECD Countries, OECD, Paris.

Ofstad S (ed.) 1994. Symposium: Sustainable Consumption. Ministry of Environment, Oslo.

OFSTED [Office for Standards in Education] 2002. Coombes Infant and Nursery School Inspection Report available at http://www.ofsted.gov.uk/

Pearce, D, A Markandya and E Barbier 1989. Blueprint for a Green Economy, Earthscan, London.

PIU 2001 Resource Productivity - Making More with Less, Performance and Innovation Unit, UK Cabinet Office, London.

Princen, T 1999. Consumption and Environment - some conceptual issues, Ecological Economics 31(3), 347-360.

Princen, T, M Maniates and K Conca 2002. Confronting Consumption. MIT Press, Boston, Mass.

Putnam, RD 2001. Bowling Alone: The Collapse and Revival of American Community, Simon and Schuster, New York.

Rayner S and E Malone (eds) 1998. Human Choice and Climate Change, Volume 1, Battelle Press, Washington DC.

Reason, P and WR Torbert 2001. 'Toward a transformational science: a further look at the scientific merits of action research', Concepts and Transformations, 6 (1) 137.

Redclift, M 1996. Wasted - counting the costs of consumption, Routledge, London.

Reisch, L 2000. 'The media and consumption: empirical evidence from audience research (in Germany), draft paper prepared for Commission on Sustainable Consumption, Oxford Centre for the Environment, Ethics and Society, Mansfield College, Oxford.

Ridley, M 1994. The Red Queen - sex and the evolution of human nature. Penguin Books, London.

Ridley, M 1996. The Origins of Virtue, Penguin Books, London.

Roodman D 1996. Paying the Piper: Subsidies, Politics, and the Environment, Worldwatch Paper 133, The Worldwatch Institute, Washington, DC.

Røpke, I 1999. The dynamics of willingness to consume, Ecological Economics 28(3) 399-420. 
Røpke, I 2001. 'New technology in everyday life - social processes and environmental impact', Ecological Economics 38, 403-422.

Rosenberg, N 1994. Exploring the Black Box: Technology, Economics and History. University Press, Cambridge, England.

Rosenblatt, R (ed) 1999. Consuming Desires: consumption, culture and the pursuit of happiness, Island Press, Washington, DC.

Russell, R and M Wilkinson 1979. Microeconomics: a synthesis of modern and neoclassical theory. John Wiley, New York.

Sagoff, M. 1988. The Economy of the Earth. Cambridge University Press, Cambridge.

Sahlins, M 1976. Culture and Practical Reason, University of Chicago Press, Chicago.

Samuelson, P 1938. A note on the pure theory of consumers' behaviour. Economica 5, 61-71.

Sanne, C 2002. Willing Consumers - or Locked In? Policies for a sustainable consumtion, Ecological Economics 42, 273-287.

Sathaye, J, D Bouille, D Biswwas, P Crabbe, L Geng, D Hall, H Imura, A Jaffe, L Michaelis, G Peszko, A Verbruggen, E Worrell and F Yamba, 2001. 'Barriers, opportunities, and market potential of technologies and practices', Chapter 5 in B. Metz, O. Davidson, R. Swart and J. Pan (eds.), Climate Change 2001: Mitigation. Contribution of Working Group III to the Third Assessment of the Intergovernmental Panel on Climate Change. Cambridge University Press. pp. 345-398.

Schor, J 1992. The Overworked American - the unexpected decline of leisure. Basic Books, New York.

Schor, J. 1998. The Overspent American - Upscaling, Downshifting and the New Consumer, Basic Books, New York.

Schumacher, E 1974. Small is Beautiful, Abacus London.

Scitovsky, T 1976. The Joyless Economy, Oxford University Press, Oxford.

Sen A 1998. The Living Standard, Chapter 16 in Crocker and Linden (eds) 1998, 287311.

Sen, A 1984. The Living Standard, Oxford Economic Papers 36 (supplement), 74-90.

Senge, P 1990. The Fifth Discipline: the Art and Practice of the Learning Organization, Random House, London.

Shove, E 2003. Comfort, Cleanliness and Convenience: the social organisation of normality, Berg Publishers, Oxford, forthcoming.

Shove, E and A Warde 1997. Noticing Inconspicuous Consumption, paper presented to the ESF TERM Programme workshop on Consumption, Everyday Life and Sustainability, Lancaster University, April 1997. http://www.comp.lancs.ac.uk/sociology/esf/inconspicous.htm

Shove, E 1999. 'Gaps, barriers and conceptual chasms: theories of technology transfer and energy in buildings', Energy Policy, Vol. 26 No. 15, pp. 1105-1112.

Simmel, G 1950. The metropolis and mental life, in Wolff, K (ed) The Sociology of George Simmel, Collier Macmillan, London.

Simms, A, J Oram, A MacGillivray and J Drury 2002. Ghost Town Britain: The threat from economic globalisation to livelihoods, liberty and local economic freedom, New Economics Foundation, London.

Slater, D 1997. Consumer Culture and Modernity, Polity Press, Cambridge.

Slesser, M 1997. Management of Greed: Bio-physical Appraisal of Economic and Environment Potential, Resource Use Institute, Edinburgh. 
Springborg, P 1981. The Problem of Human Needs and the Critique of Civilisation, George Allen and Unwin, London.

Staats, HJ and P Harland 1995. The Ecoteam Program in the Netherlands. Study 4: A Longitudinal Study on the Effects of the EcoTeam Program on Environmental Behaviour and its Psychological Backgrounds, Summary Report, E\&M/R-95/57, Centre for Energy and Environmental Research, Faculty of Social and Behavioural Sciences, Leiden University, the Netherlands.

Stein, B 1995. The Machine Makes the Man, Wall Street Journal 2005 (June 13), 30.

Stenstadvold, M 1995. Institutional Constraints to Environmentally Sound Integrated Land-Use and Transport Policies: Experiences from the Norwegian Integrated Land-Use and Transport Planning Scheme. In The 23rd European Transport Forum, Coventry, England, 11-15 September, 1995. PTRC, London.

Stern, PC 1986. "Blind spots in policy analysis: what economics doesn't say about energy use", Journal of Policy Analysis and Management, Vol. 5, No. 2, pp. 200-227.

Tainter, J 1996. 'Complexity, problem solving and sustainable societies', in Getting Down to Earth: Practical Applications of Ecological Economics, [R. Costanza, O. Segura and J. Martinez-Alier (eds.)], Island Press, 1996. pp. 61-76.

Taylor, C 1989. Sources of the self: The making of the modern identity. Cambridge, MA: Cambridge University Press.

Thompson, M and S Rayner 1998. Cultural discourses, Chapter 4 in S. Rayner and E. L. Malone (eds.) Human Choice and Climate Change. Volume 1. The Societal Framework, Battelle Press, Columbus, Ohio, pp. 265-343.

Thompson, M, R Ellis and A Widalsky, 1990. Cultural Theory, Westview Press, Boulder, CO.

Tooby, J and L Cosmides 1990. The past explains the present: emotional adaptations and the structure of ancestral environments. Ethology and Sociobiology 11: 375421.

Torbert, WR 2001. 'The practice of action inquiry', Chapter 23 in P. Reason and H. Bradbury (eds.) Handbook of Action Research, Sage, London.

Torbert, WR, D Fisher and D Rooke 2001. Personal and Organisational Transformations Through Action Research, Edge/Work Press, Boston, MA.

Trainer, T. 1996. Towards a Sustainable Economy - the Need for Fundamental Change. Oxford: Jon Carpenter Publishing.

Trivers, R 1971. The evolution of reciprocal altruism, Quarterly Review of Biology 46, 35-56.

UN 2002a. Johannesburg Declaration, United Nations, New York.

UN 2002b. Johannesburg Plan of Implementation, United Nations, New York.

UNDP 1998. Human Development Report 1998, Oxford University Press, Oxford and New York.

UNED-UK 1999. Gender and Sustainable Consumption: bridging policy gaps, United Nations Environment and Development (UK), London.

UNEP 2001. Consumption Opportunities: Strategies for change, United Nations Environment Programme, Paris.

van den Bergh, J.C.J.M., Ferrer-i-Carbonell, A., Munda, G., 2000. Alternative Models of Individual Behaviour and Implications for Environmental Policy, Ecological Economics 32(1), 43-61. 
Veblen, T 1899. The Theory of the Leisure Class, 1998 edition, Great Minds Series, Prometheus Books, London.

Vlek, C, L Reisch and G Scherhorn, 2000. Transformation of Unsustainable Consumer Bheaviours and Consumer Policies, Research Report COV 00-04, Centre for Environmental and Traffic Psychology, University of Groningen, the Netherlands.

von Weizsäcker, E, A Lovins and L Hunter Lovins 1997. Factor Four - Doubling Wealth, Halving Resource Use. Earthscan, London.

Wachtel, P 1989. The Poverty of Affluence, New Society Publishers, Philadelphia.

Wackernagel, ML 2000. The Footprints of Nations Study, spreadsheets downloaded from http://www.rprogress.org/resources/nip/ef/ef_nations.html on 21 June 2002.

Walker, P 1997. Community Visions Resource Pack, London, New Economics Foundation.

Warde, A 1996. Afterword: the future of the sociology of consumption, in Edgell, S, K Hetherington and A Warde (eds) Consumption Matters: the production and experience of consumption, Blackwell, Oxford.

WCED 1987. Our Common Future, The Brundtland Report, Oxford University Press, Oxford.

Welford, R 2000. Corporate Environmental Management, Volume 3, Towards Sustainable Development, Earthscan, London.

WI [Women's Institute] 1993. Pathway to the 21st Century : Celebrating our Communities, WI Website: http://www.womens-institute.org.uk/camppathway.shtml.

Wilber, K 2000. Integral Psychology, Shambala, Boston, MA

Wilhite, H 1998. 'Cultural aspects of consumption', working paper prepared for Second European Science Foundation Workshop on Consumption, Everyday Life and Sustainability, Lancaster University, England. See http://www.lancs.ac.uk/users/esf/wilhit.htm

Wilk, R 1998. 'Emulation, imitation, and global consumerism.' Organization \& Environment 11(3): 314-333.

Worcester, R 1998. More than Money, in Christie I and L Nash (eds) The Good Life, Demos, London.

Wright, R 1994. The Moral Animal - why we are the way we are: the new science of evolutionary psychology, Abacas, London. 